\title{
Robust Measurement of National Technological Progress
}

\author{
Stefano Zambellia ${ }^{\mathrm{a}}$, Thomas Fredholm ${ }^{\mathrm{b}}$, Ragupathy Venkatachalam ${ }^{\mathrm{c}}$ \\ ${ }^{a}$ Department of Economics and Management, University of Trento, Via Inama 5, 38122 Trento, Italy \\ ${ }^{b}$ Department of Economics and Management, University of Trento, Via Inama 5, 38122 Trento, Italy \\ 'Institute of Management Studies, Goldsmiths, University of London, New Cross, London, SE14 6NW, UK.
}

\begin{abstract}
We propose a measure of technological progress based on the information embedded in standard input-output tables. A connection is established between the quantities necessary as inputs, the associated output and auxiliary prices. It is argued that the wage-profit frontiers and the associated production prices together provide a robust basis for measuring technological progress and productivities. The computation of the wage-profit frontiers is a non-trivial exercise because of high combinatorial complexity. An algorithm that renders this computation feasible is presented. We analyze technological progress and productivities among 30 countries between 1995-2011 using the latest multi-regional input-output data.
\end{abstract}

Keywords: Technological Change, Input-Output analysis, Wage Profit Frontier, Productivity

\section{Introduction}

In this paper we propose a measure of technological progress of a region or nation based on the information embedded in its standard input-output tables by computing the wage-profit curves, and the wage-profit frontier. Our aim is to measure the technical efficiency of the economic system, but we depart from the conventional practice of estimating a surrogate physical aggregate production function ${ }^{1}$. Instead, we resort to computing the wage-profit frontier ${ }^{2}$.

We do not aggregate quantities that have conceptually different physical units. We do not follow methods that require the computation of an aggregate production function as proposed by Farrell (1957). He proposed a way to measure productive

\footnotetext{
Email address: stefano .zambelli@unitn. it (Stefano Zambelli)

${ }^{1}$ For an investigation on the aggregate production function and its neoclassical properties see the companion paper Zambelli (2017).

${ }^{2}$ Throughout this paper, we have used the term wage-profit frontier consistently for reasons of clarity, even though one find other terms by which it is referred to in the literature, such as: factor price frontier, as in Samuelson (1962, p.195), Hicks (1965, p.140), Diamond (1965, p.1134), or optimal transformation frontier (Bruno, 1969, p.39). Though different terms have been used, they are all concerned with the choice of efficient techniques (Robinson, 1953; Pasinetti, 1966; Garegnani, 1966; Bruno, 1969; Sato, 1974; Pasinetti, 1977).
} 
efficiency by assuming the existence of a universally optimal (or efficient) production function, whose isoquants are consistent with neoclassical postulates (as defined, for example, in Shephard (1970, p.14) or Sato (1974). As noted by Afriat (2003, pp.119-20), Farrell's approach and the more recent Data Envelopment Analysis (Charnes et al., 1978)) are substantially the same. While the Data Envelopment Analysis does not rely on a specific functional form, it assumes that the underlying production function is neoclassical, by imposing convexity (Petersen, 1990; Bogetoft, 1996; Bogetoft et al., 2000). Recent studies trying to assess technological progress and/or productivity growth rely on versions of Data Envelopment Analysis, which use simple aggregate, neoclassical production function of the type $Y=F(K, L, A)$, for example, Kumar and Russell (2002), O'Mahony and Timmer (2009) and Fried et al. (2008) ${ }^{3}$. Instead, we generate theoretically robust measures based on industry specific production prices. By comparing the production prices associated with country specific input-output tables, we are able to identify an efficient set of discrete methods of production. This efficient set of methods is used for the construction of indexes to assess systemic and sectoral technical efficiency and technological progress ${ }^{4}$.

In Section 2, we review the notion of a wage-profit curve and derive the production prices associated to national input-output tables. In Section 3 we define the wage-profit frontier as the outer envelope computed from all the possible wage-profit curves. While mathematical notion of an envelope is conceptually straightforward, the brute force algorithm associated with the computation of such an envelope that takes in to account every single point is computationally infeasible. This is explained in Appendix A.1. We construct an efficient algorithm (FVZ-algorithm $)^{5}$, which exploits a result by Bruno et al. (1966) and Bharadwaj (1970), enabling us to compute a global and empirically based wage-profit frontier. This is done for the first time in this paper to the best of our knowledge. This algorithm is described in Appendix A.2. FVZ-algorithm allows the computation of properly tailored wage-profit frontiers and the associated industry level production prices. We apply this algorithm to the input-output data for different countries that has been recently made available and the description of this database is given in Section 4. The wage-profit curves and frontiers thus constructed and the associated production prices are used to compute several indexes of economic performance (Section 5).

Subsequently, three new indexes of technological progress are presented. The first of the three, the wage-profit curve ratio $\left(\mathcal{W P}_{\mathcal{P}}{ }^{\text {ratio }}\right)$, measures the difference between the global intertemporal wage-profit frontier with respect to national wage-profit frontiers

\footnotetext{
${ }^{3}$ For an excellent, critical discussion on the use of aggregate production functions in measuring technical change, see Felipe and McCombie (2013). Zambelli (2017) provides empirical support for the results of Felipe and McCombie (2013), demonstrating that the aggregate production function does NOT exhibit neoclassical properties. Zambelli (2017) uses the algorithm presented here in the Appendix A. 2 and the same data set used here.

${ }^{4}$ This set of methods is equivalent to the Production Possibility Frontier. The Production Possibility Frontier is often estimated with production function which are highly aggregated, but not for the cases in which we have, as it is in our case, a large number of sectors or industries.

${ }^{5} \mathrm{FVZ}$ stands for Fredholm-Velupillai-Zambelli.
} 
(Section 6). The second index is a measure of sectoral technological progress based on the relative contributions at each sectoral level to the set of methods that define the wage-profit frontier (Section 7 ). The third, the technological progress index or $\mathcal{T} \mathcal{P}$-index, is based on the advanced methods of production that belong to the global intertemporal wage-profit frontier, see below (Section 8). It measures aggregate national technological progress based on the relative contributions at each sectoral level to the set of methods that define the best technology frontier. In Section 9 the results of the computations are discussed. Section 10 presents some concluding remarks.

\section{Production Methods, Wage-Profit Curves and Production Prices}

We base our analysis on the information embedded in input-output tables, from which we derive the methods of production. We start with a multiple-input framework where different production methods (activities) are available for producing a single output. A method is a combination of (multiple) inputs that go into producing different outputs ${ }^{6}$. From the input-output tables, we empirically observe that $b_{i}$ units of commodity $i$ can be produced with $s_{i}$ different alternative methods ${ }^{7}$

$$
\phi\left(z_{i},:, i\right): a_{i 1}^{z_{i}}, a_{i 2}^{z_{i}}, \ldots, a_{i n}^{z_{i}}, \ell_{i}^{z_{i}} \mapsto b_{i}^{z_{i}}
$$

where: $i=1, \ldots, n ; j=1, \ldots, n ; \quad z_{i}=1, \ldots, s_{i} . a_{i j}^{z_{i}}$ is the input of commodity $j$ in producing a good $i$ using a method $z_{i} . s_{i}$ is the number of available methods for producing the good $i$ and $n$ is the number of goods.

The set of methods for producing good $i$ can be represented in matrix notation as:

$$
\Phi\left(1: s_{i}, 1:(n+2), i\right)=\left[\begin{array}{ccccc}
a_{i 1}^{1} & \ldots & a_{i n}^{1} & \ell_{i}^{1} & b_{i}^{1} \\
a_{i 1}^{2} & \ldots & a_{i n}^{2} & \ell_{i}^{2} & b_{i}^{2} \\
\vdots & \vdots & \vdots & \vdots & \vdots \\
a_{i 1}^{s_{i}} & \ldots & a_{i n}^{s_{i}} & \ell_{i}^{s_{i}} & b_{i}^{s_{i}}
\end{array}\right]
$$

\footnotetext{
${ }^{6}$ In this article we use the term "method" to identify the observations embedded in the Input-Output tables, where observed inputs are linked with observed outputs. Nothing is implied regarding the functional form of the underlining production function. For instance, the assumption of constant returns to scales is not implied, but it is not excluded as well. What it is assumes, however, is the divisibility of inputs and of outputs. Input-Output tables do not contain information on the actual functional form of the production function, whether it is with constant, increasing or decreasing returns to scale. This classification is potentially misleading (Sraffa, 1925, 1926). The results presented in this paper represent a benchmark. For reasons of space, we do not present a detailed account of the distinction that needs to be made between divisibility and constant returns to scale assumptions.

${ }^{7}$ The notation is here slightly different from standard mathematical notation. This is a notation familiar to the users of Matlab for multiple dimension arrays. The numbers inside parenthesis identify the dimension, i.e. rows, columns, $3^{\text {rd }}$-dimension, $4^{\text {th }}$-dimension and so on. The symbol : stands for all the numbers in that dimension, and $1: s$ means from 1 to $\mathrm{s}$ and so on. $\phi\left(z_{i},:, i\right)$ identifies an entry for the multiple dimension array $\phi$, where $z_{i}$ identifies the row, : means for all columns and $i$ the third dimension.
} 
The cardinality of the above set of methods can be very large and subsets of the above methods can exhibit, in principle, a great variety of mathematical properties. For example, some subsets of methods can be such that they satisfy the standard neoclassical properties and some may not.

The set of all the available methods is given by the following set of activities $\Phi=\{\Phi(:,:, 1) \cup \Phi(:,:, 2) \ldots, \Phi(:,:, n)\}^{8}$. Hence, a $n$-commodity output vector can be generated by using one combination of the methods, which belongs to set $\boldsymbol{\Phi}$. There are a total $s=\prod_{i=1}^{n} s_{i}$ of these combinations. Given one of these combinations, $\mathbf{z}=\left[z_{1}, z_{2}, \ldots, z_{n}\right]^{\prime}$, we have one production possibility. The set representing the means of production (other than labour) is given by the following matrix:

$$
\mathbf{A}^{\mathbf{z}}=\left[\begin{array}{c}
\boldsymbol{\Phi}\left(z_{1}, 1: n, 1\right) \\
\boldsymbol{\Phi}\left(z_{2}, 1: n, 2\right) \\
\vdots \\
\boldsymbol{\Phi}\left(z_{n}, 1: n, n\right)
\end{array}\right]=\left[\begin{array}{cccc}
a_{11}^{z_{1}} & a_{12}^{z_{1}} & \ldots & a_{1 n}^{z_{1}} \\
a_{21}^{z_{2}} & a_{22}^{z_{2}} & \ldots & a_{2 n}^{z_{2}} \\
\vdots & \vdots & \vdots & \vdots \\
a_{n 1}^{z_{n}} & a_{n 2}^{z_{n}} & \ldots & a_{n n}^{z_{n}}
\end{array}\right] ;
$$

The labour requirement is given by the following vector:

$$
\mathbf{L}^{\mathbf{z}}=\left[\begin{array}{c}
\boldsymbol{\Phi}\left(z_{1}, n+1,1\right) \\
\mathbf{\Phi}\left(z_{2}, n+1,2\right) \\
\vdots \\
\mathbf{\Phi}\left(z_{n}, n+1, n\right)
\end{array}\right]=\left[\begin{array}{c}
\ell_{1}^{z_{1}} \\
\ell_{2}^{z_{2}} \\
\vdots \\
\ell_{n}^{z_{n}}
\end{array}\right]
$$

The quantity produced by employing means of production $\mathbf{A}^{\mathbf{z}}$ and labor $\mathbf{L}^{\mathbf{z}}$ may be represented with the following diagonal matrix where the diagonal entries are the quantity produced per each sector:

$$
\mathbf{B}^{\mathbf{z}}=\operatorname{diag}\left(\left[\begin{array}{c}
\boldsymbol{\Phi}\left(z_{1}, n+2,1\right) \\
\boldsymbol{\Phi}\left(z_{2}, n+2,2\right) \\
\vdots \\
\mathbf{\Phi}\left(z_{n}, n+2, n\right)
\end{array}\right]\right)=\operatorname{diag}\left(\left[\begin{array}{c}
b_{1}^{z_{1}} \\
b_{2}^{z_{2}} \\
\vdots \\
b_{n}^{z_{n}}
\end{array}\right]\right) ;
$$

The notation can be simplified: $\mathbf{z}$ may be taken to represent any production system composed of the triple $\left(\operatorname{diag}(\mathbf{x}) \mathbf{A}^{\mathbf{z}}, \operatorname{diag}(\mathbf{x}) \mathbf{L}^{\mathbf{z}}, \operatorname{diag}(\mathbf{x}) \mathbf{B}^{\mathbf{z}}\right)$ where $(\mathbf{x})$ is the intensity of utilization of the methods (activity levels) and diag $(\mathbf{x})$ is the diagonal matrix of vector $\mathbf{x}$. The system is defined as being 'productive for all cases in which $\mathbf{x}$ is such that $\mathbf{x}^{\prime}\left(\mathbf{B}^{\mathbf{z}}-\mathbf{A}^{\mathbf{z}}\right) \geq 0$. It should be noted that the activity level $\mathbf{x}$ that would allow for the system to be productive need not always exist. In that case the particular combination $\mathbf{z}$ is not viable (Chiodi, 1998).

Given a system of methods, $\mathbf{z}$, and an the endowment of the primary factors of

\footnotetext{
${ }^{8}$ Alternatively, one can view $\boldsymbol{\Phi}$ as a multi-dimensional array, whose maximum number of rows is given by $\max \left\{s_{1}, s_{2}, \ldots, s_{i}, \ldots, s_{n}\right\}$, the number of columns is $n+2$ (the $\mathrm{n}$ inputs, labour and output) and the number of matrices are equal to the number of goods. Each matrix $\Phi(:,:, i)$ contains information about all the possible discrete methods.
} 
production, which here is labour $\mathbf{e}^{\prime} \mathbf{L}^{\mathbf{z}}$ (where $\mathbf{e}$ is the summation vector), we define the $n$-dimensional production possibility frontier as:

$$
\mathbf{\Omega}^{\mathbf{z}}=\left\{\overline{\mathbf{x}}^{\mathbf{z}}: \mathbf{x}^{\prime} \mathbf{L}^{\mathbf{z}}=\mathbf{e}^{\prime} \mathbf{L}^{\mathbf{z}} \wedge \mathbf{x}^{\prime}\left(\mathbf{B}^{\mathbf{z}}-\mathbf{A}^{\mathbf{z}}\right) \geq 0\right\} \text { with } \mathbf{x} \geq \mathbf{0}
$$

Once a combination of methods $\mathbf{z}$ has been chosen, we have the problem of evaluating and comparing it with respect to another combination. Any intricate productive system can be examined from the point of view of (a) the quantities that are used as factors of production or (b) the values or prices that are necessary for that productive system to reproduce itself. In this paper we evaluate the quality of a set of methods by studying the properties of the values or prices as in (b).

Note that the prices used for the derivation of indexes are not market prices. Instead, these are computed analytical prices that are based on the actual observed quantities. These prices can be interpreted in many different ways. For instance, they can be seen as Adam Smith's natural prices or Ricardo-Marx-Sraffa's production prices, Seton's eigenprices, long term competitive equilibrium prices; Walrasian market clearing prices, shadow prices and so on. Here we will chose to evaluate the collection of methods in terms of production prices (as defined, for example, in Sraffa (1960) or Leontief $(1985))^{9}$.

Given a chosen system, $\mathbf{z}$, and a uniform rate of profits $r^{10}$ and the activity level $\mathbf{x}$, the production prices that would assure the system to remain productive for future periods are precisely those which allow the following accounting relation to hold:

$$
\operatorname{diag}(\mathbf{x}) \mathbf{A}^{\mathbf{z}} \mathbf{p}(1+r)+\operatorname{diag}(\mathbf{x}) \mathbf{L}^{\mathbf{z}} w=\operatorname{diag}(\mathbf{x}) \mathbf{B}^{\mathbf{z}} \mathbf{p}
$$

For a given rate of profits $r$ and a uniform wage rate $w$, there exists a price vector $\mathbf{p}$ that would allow the system to remain productive for the subsequent periods as well:

$$
\mathbf{p}^{\mathbf{z}}(r, w, \mathbf{x})=\left[\operatorname{diag}(\mathbf{x}) \mathbf{B}^{\mathbf{z}}-\operatorname{diag}(\mathbf{x}) \mathbf{A}^{\mathbf{z}}(1+r)\right]^{-1} \operatorname{diag}(\mathbf{x}) \mathbf{L}^{\mathbf{z}} w
$$

An important result in this context is that for a given combination of methods $\mathbf{z}$ (i.e., any triple $\left.\operatorname{diag}(\mathbf{x}) \mathbf{B}^{\mathbf{z}}, \operatorname{diag}(\mathbf{x}) \mathbf{A}^{\mathbf{z}}, \operatorname{diag}(\mathbf{x}) \mathbf{L}^{\mathbf{z}}\right)$ the re-proportion matrix $\operatorname{diag}(\mathbf{x})$ does not influence the determination of the price vector $\mathbf{p}$. This is known in the literature as the Non-Substitution Theorem ${ }^{11}$. This implies that the prices are determined as a function of the set of methods and they do not depend on the intensity. Therefore the

\footnotetext{
${ }^{9}$ The relation between Sraffian Schemes and Leontief's Input-Output Tables is investigated in several contributions in the literature. In particular see Pasinetti (1977, Chs. 1-5) for theoretical foundations and Kurz and Salvadori (2006) for a textual comparison between the writings of Leontief and Sraffa. On the choice of techniques see also Pasinetti (1977, Ch. 6) and Kurz and Salvadori (1995, Ch. 4).

${ }^{10}$ Here for simplicity we consider the case of the uniform rate of profit. We follow (Sraffa, 1960). Nevertheless it is important to stress that the system may reproduce itself also for the cases in which there are differences in the rates of profits.

${ }^{11}$ On the origins of the non-substitution-theorem, see Arrow (1951), Koopmans (1951), Samuelson (1951). A more recent treatment is presented in Mas-Colell et al. (1995), pp.159-60. See also Zambelli (2004, footnote 2, p. 105), Pasinetti (1977, Ch. 6)
} 
properties of the prices, as we will see below, may have a high degree of generality because they would depend on the observed methods (and distribution), but not on the actually produced or demanded quantities.

Equation 2.8 may be simplified into:

$$
\mathbf{p}^{\mathbf{z}}(r, w)=\left[\mathbf{B}^{\mathbf{z}}-\mathbf{A}^{\mathbf{z}}(1+r)\right]^{-1} \mathbf{L}^{\mathbf{z}} w
$$

We then choose a numéraire, a vector composed of different proportion of the $n$ produced goods forming the input-output tables,

$$
\eta^{\prime} \mathbf{p}^{\mathbf{z}}(r, w)=1
$$

we are now in a position to define the wage-profit curve. By substituting 2.9 into 2.10 we obtain the wage-profit curve associated with the set of methods $\mathbf{z}$ :

$$
w^{\mathbf{z}}(r, \eta)=\left[\eta^{\prime}\left[\mathbf{B}^{\mathbf{z}}-\mathbf{A}^{\mathbf{z}}(1+r)\right]^{-1} \mathbf{L}^{\mathbf{z}}\right]^{-1}
$$

where $r \in\left[0, \mathcal{R}^{\mathbf{z}}\right]$ and $\mathcal{R}^{\mathbf{z}}$ is the maximum rate of profit of system $\mathbf{z}$. This is the wageprofit curve associated with system $\mathbf{z}$, for the case where the profit rates are uniform for all industries.

Substituting 2.11 into 2.9 we obtain the price vector

$$
\mathbf{p}^{\mathbf{z}}(r, \eta)=\left[\mathbf{B}^{\mathbf{z}}-\mathbf{A}^{\mathbf{z}}(1+r)\right]^{-1} \mathbf{L}^{\mathbf{z}}\left[\eta^{\prime}\left[\mathbf{B}^{\mathbf{z}}-\mathbf{A}^{\mathbf{z}}(1+r)\right]^{-1} \mathbf{L}^{\mathbf{z}}\right]^{-1}
$$

The price vector $\mathbf{p}^{\mathbf{z}}(r, \eta)$ is a function of the particular set of methods $\mathbf{z}$ and of the rate of profits $r$. These are auxiliary prices that would allow for the accounting balance between buyers and sellers of the factors of productions such that the same production activity could take place during next cycle.

\section{The Wage Profit Frontier and Technological Progress}

We attempt to measure technological progress by comparing the prices associated with the employment of old and new methods. The system is said to exhibit a technological improvement when the auxiliary price is lower than the previous price or, when, for given profit rates $r$, the associated wage rate, $w^{\mathbf{z}}$, is higher than earlier.

Although the wage-profit curve, eq. 2.11, is a well known relation, in the past its empirical importance may have been underestimated. For each combination of methods $\mathbf{z}$, there is a corresponding wage-profit curve. The outer envelope of all possible wageprofit curves is the wage-profit frontier. For a given subset of combination of methods $\boldsymbol{E}=\left\{\mathbf{z}_{1}, \mathbf{z}_{2}, \ldots, \mathbf{z}_{\mathrm{m}}\right\}$ of $\boldsymbol{\Phi}$, it is defined as

$$
w_{\boldsymbol{E}}^{\mathrm{WPF}}(r, \eta)=\max \left\{w^{\mathbf{z}_{1}}(r, \eta), w^{\mathbf{z}_{2}}(r, \eta), \ldots, w^{\mathbf{z}_{\mathrm{m}}}(r, \eta)\right\}
$$

The domain of $w_{E}^{\mathrm{WPF}}(r, \eta)$ is composed of $v$ intervals. The junction between the different intervals are called switch points - points where the dominance of one wageprofit curve is replaced by another one. 


$$
r \in\left[\left[0, \widehat{r}_{1}\left[\cup \left[\widehat{r}_{1}, \widehat{r}_{2}\left[, \ldots,\left[\widehat{r}_{v-2}, \widehat{r}_{v-1}\right] \cup\left[\widehat{r}_{v-1}, \mathcal{R}_{E}^{W P F}\right]\right]\right.\right.\right.\right.
$$

where $\widehat{r}_{k}(k=1,2, \ldots, v-1)$ are the switch points and $\mathcal{R}_{E}^{W P F}$ is the maximum rate of profit of $w_{E}^{\mathrm{WPF}}(r, \eta)$. These intervals are relatively few with respect to the very large number of possible combination of methods belonging to $\boldsymbol{E}$.

Each interval, $k$, is the domain of a wage-profit curve that was generated by the set of methods $\mathbf{z}_{\{k\}}$. The whole set of methods that contribute to $w_{\boldsymbol{E}}^{\mathrm{WPF}}(r, \eta)$ may be arranged in matrix notation as:

$$
\mathbf{Z}_{\boldsymbol{E}}^{\mathrm{WPF}}=\left[\mathbf{z}^{\{1\}}, \mathbf{z}^{\{2\}}, \ldots, \mathbf{z}^{\{k\}}, \ldots, \mathbf{z}^{\{v\}}\right]=\left[\begin{array}{cccc}
z_{11}^{\{1\}} & z_{12}^{\{2\}} & \ldots & z_{1 v}^{\{v\}} \\
z_{21}^{\{1\}} & z_{22}^{\{2\}} & \ldots & z_{2 v}^{\{v\}} \\
\vdots & \vdots & \vdots & \vdots \\
z_{n 1}^{\{1\}} & z_{n 2}^{\{2\}} & \ldots & z_{n v}^{\{v\}}
\end{array}\right]
$$

The derivation - i.e. computation - of the set of methods at the frontier derived from a large number of empirical set of methods is the major and innovative contribution of this paper.

Several characteristics of the wage-profit curves and the wage-profit frontier are useful for analyzing the performance of economic regions and to construct relevant indexes. $^{12}$

1. "At a switch point the adjacent production system differs in the method of production for only one of the commodities common to them (Bharadwaj (1970) (p.423), emphasis added)";

2. At switch points the production prices of each commodity are the same independently from whether they are computed with one or the other of the two set of methods that coexist at the switch point (Pasinetti, 1977, p.158).

3. The wage-profit curves are strictly decreasing as the rate of profit decreases (Pasinetti, 1977, p.159).

4. The wage-profit curves and frontiers are scale independent. This result follows from the non-substitution theorem. Hence, two different productive systems, say, those associated with a small and a big country, can be compared using this framework.

5. The methods determining the wage-profit frontier are independent of the numéraire.

6. The wage-profit curves, eq. 2.11 are associated with the quantities that could actually be produced using a given combinations of methods, $\mathbf{z}$ and by employing total labour $\mathbf{e}^{\prime} \mathbf{L}^{\mathbf{z}}$. This produced vector of goods is a point in the production possibility frontier (eq. 2.6). Clearly, for a given set of profit rates, if $w^{\overline{\mathbf{z}}}>w^{\mathbf{z}}$,

\footnotetext{
${ }^{12}$ See also Pasinetti (1977), Ch.6, Section 4.3, Analytical properties of the technological frontier.
} 
it means that the $w^{\overline{\mathbf{z}}}$ has a higher purchasing power with respect to $w^{\mathbf{z}}$ for the associated auxiliary prices. Hence we can claim that the production associated with the highest wage profit curve is desirable or more efficient ${ }^{13}$. This is important because it allows the comparison and choice of different bundles of produced goods. This is particularly relevant when we consider that the values of different wage profit curves and production prices are all computed in terms of a common "physical" numéraire. Hence, comparing the n-dimensional production possibility frontiers, $\Omega^{\overline{\mathbf{z}}}$ and $\Omega^{\mathbf{z}}$ becomes straightforward: the most efficient system, ceteris paribus, would be the one that has the highest wage-profit frontier.

7. Consider two wage-profit curves, $w^{\mathbf{z}_{a}}(r, \eta)$ and $w^{\mathbf{z}_{b}}(r, \eta)$ where the set of methods differ only for the production of the $k^{\text {th }}$ product so that $\mathbf{z}_{\mathbf{a}}=\left[z_{1}, z_{2}, \ldots,-\right.$ $\left.z_{a}, \ldots, z_{n}\right]^{\prime}$, and $\mathbf{z}_{\mathbf{b}}=\left[z_{1}, z_{2}, \ldots, z_{b}, \ldots, z_{n}\right]^{\prime}$. For a given profit rate $r$ any linear combination of the $k^{\text {th }}$ methods $z_{a}$ and $z_{b}$ is associated with a wage-profit curve, let us call it $w^{\mathbf{z}_{a} \ldots \mathbf{z}_{b}}$, which will never dominate the two original wage-profit curves. It is never the case that $w^{\mathbf{z}_{a} \ldots \mathbf{z}_{b}}>\max \left\{w^{\mathbf{z}_{a}}, w^{\mathbf{z}_{b}}\right\}$. This is important in order to compare two or more wage-profit curves and for deriving the wage-profit frontier because it excludes all possible linear combinations as they will not be efficient (Mas-Colell et al., 1995, pp.159-60).

8. Comparison between two wage-profit curves is independent of the cardinality of their productive systems. Two systems having different cardinality, say $n$ and $m$, can still be compared as long as they have the same numéraire. The only requirement is that the numéraire is a transformation based on the subset of commodities, which are common to both systems.

9. Clearly, not all wage-profit curves associated with $\boldsymbol{E}$ contribute to the formation of the wage-profit frontier, $w_{\boldsymbol{E}}^{\mathrm{WPF}}$. The subset of methods of $\boldsymbol{E}$ that enter the frontier represent the most productive system of methods. For the measurement of productivity and technological progress we will make use of the information about $w_{E}^{\mathrm{WPF}}$, associated production prices and the methods that contribute to the frontier. An example of an actual wage-profit frontier is illustrated below in Figure 5.1 .

10. Whether the wage-profit frontier, $w_{E}^{\mathrm{WPF}}$, is consistent with the neoclassical framework will depend on the particular structure associated with the set of methods. Hence, this approach is more general and therefore we abstain from discussing whether or not the production structure is neoclassical in this paper.

\section{Data and the Choice of Numéraire}

We use data from the World Input-Output Database (Timmer, 2012) which is publicly available and it provides detailed input-output data at the industrial level for 35 in-

\footnotetext{
${ }^{13}$ Given alternative sets or combinations of methods, the combination that produces, ceteris paribus, the highest vector of social surplus is what is referred to as 'efficient'.
} 


\begin{tabular}{clclcl}
\hline Code & Country Name & Code & Country Name & Code & Country Name \\
\hline AUS & Australia & FIN & Finland & KOR & Korea \\
AUT & Austria & FRA & France & MEX & Mexico \\
BEL & Belgium & GBR & Great Britain & NLD & Netherlands \\
BRA & Brazil & GRC & Greece & POL & Poland \\
CAN & Canada & HUN & Hungary & PRT & Portugal \\
CHN & China & IDN & Indonesia & RUS & Russia \\
CZE & Czech Republic & IND & India & SWE & Sweden \\
DEU & Germany & IRL & Ireland & TUR & Turkey \\
DNK & Denmark & ITA & Italy & TWN & Taiwan \\
ESP & Spain & JPN & Japan & USA & United States \\
\hline
\end{tabular}

dustries from 1995-2011. The data set is composed of national input-output tables of 40 countries that includes 27 EU countries and 13 other major industrial countries. These tables provide information on the inter-industry supply and use and the share of output from industries that go into production in a particular industry, along with primary factors. It also has data on final consumption expenditure of households, government and gross fixed capital formation at the industry level. This constitutes a comprehensive data set in which all inter-industry flows are properly accounted. For more details regarding the construction of Input-Output tables in WIOD database, see Dietzenbacher(2013). The unique aspect of the Social and Economic Accounts (SEA) is that it offers data at the industry level. We use this data to compute yearly and inter-temporal wage-profit frontiers. For a detailed description of the data set, see Timmer (2012).

In this exercise, we have confined ourselves to a subset of 30 countries. In our analysis, we have reduced the total sectors or industries to 31 (the list of the sectors is reported below in the Table 7.1). The reason for doing so is the following: Since this is production oriented approach, we are considering only those industries that belong to the core of the 'production' system. Although the contribution of the 4 excluded sectors in terms of services to the whole system and their impact on the well being of the individuals may be high, their direct impact on the core of the production is negligible. In other words, their direct contribution to the production of other sectors $^{14}$ is negligible. Out of the total of 40 countries, we restrict our analysis to 30 of them there by excluding countries which are relatively small in terms of their output as well as their diversity in production (see Table 4.1). The National Input-Output tables (NIOT) have been adjusted so as to include the imports of means of production. Hence, the methods associated with each sector would be the inputs of internally produced goods plus the inputs of the imported goods. All the current period values have been appropriately adjusted using price indexes. For this, we have used the data on price series that are available in the Social and Economic Accounts (SEA) section

\footnotetext{
${ }^{14}$ These sectors are: Public Administration and Defence, Compulsory Social Security; Education; Health and Social Work; Private Households with Employed Persons.
} 
of the WIOD database (Timmer, 2012).

Once the above adjustments have been made, we organize the means of production, labour inputs and the gross output as in the multi-dimensional matrix $\boldsymbol{\Phi}$. This enables us to enumerate all the possible combinations of methods of production with the vectors $\mathbf{z}$ and associate them to production systems formed by the triple: $\mathbf{A}^{\mathbf{z}}$ (eq. 2.3), $\mathbf{L}^{\mathbf{z}}$ (eq. 2.4), $\mathbf{B}^{\mathbf{z}}($ eq.2.5). An important feature of the approach in this paper is that all the different values - wages and production prices, are measured with respect to the same physical numéraire, $\eta$. The choice of such common standard is an important question and it needs to be studied with care. But for reasons of space we leave this investigation to a future exercise. In this paper we have chosen the agricultural sector as the common numéraire, which we feel is a relevant measure, given the historical debates on this topic and given the aims of our exercise. Therefore, we represent $\eta^{\prime}=[1,0, \ldots, 0]$. Once the data is appropriately arranged, we do the following:

1. We compute the country-specific wage-profit curves, $w^{\mathbf{z}}(r, \eta)$ as in eq. 2.11 and the associated production prices, $\mathbf{p}^{\mathbf{z}}(r, \eta)$ as in eq. 2.12 for each year.

2. We apply the FVZ-algorithm to find the efficient set of methods $\mathbf{Z}_{\boldsymbol{E}_{t}}^{\mathrm{WPF}}$ (see eq. 3.3).

3. The yearly wage-profit frontiers $\left(w_{\boldsymbol{E}_{1995}}^{\mathrm{WPF}}, w_{\boldsymbol{E}_{1996}}^{\mathrm{WPF}}, \ldots w_{\boldsymbol{E}_{2008}}^{\mathrm{WPF}} w_{\boldsymbol{E}_{2009}}^{\mathrm{WPF}}\right)$, the inter-temporal wage-profit frontier, $w_{\boldsymbol{\Phi}}^{\mathrm{WPF}}(r, \eta)$, and the production prices are computed.

4. We define and compute relevant indexes of performance for each country $j$.

5. We then compare the different indexes and provide the rankings according to country performance.

\section{Empirical results: the wage-profit curves, yearly and intertemporal wage-profit frontiers}

Figure $5.1^{15}$ reports the wage-profit frontier relative to the year $2011, w_{\boldsymbol{E}_{2011}}^{\mathrm{WPF}}$. We see that the frontier is made of contributions due to many wage-profit curves, which are

\footnotetext{
${ }^{15}$ Most published empirical work focus on the computation of wage-profit curves, as opposed to the computation of the empirical wage-profit frontier. Major reasons for this are the lack of appropriate data and the lack of an algorithm that would allow the computation of the wage-profit frontier for a large set of available methods, $\Phi$. The existing empirical literature on this is confined to the cases in which only two or three alternative methods were considered. Hence, the total number of wage profit curves to compute was very limited. Leontief (1985) computes the wage-profit curve associated with the USA Input-Output Table relative to 1979. Technological change is subsequently studied by making hypothetical changes in some individual methods. In fact, the analysis was conducted on the wage-profit curve and not on the wage-profit frontier.

A more complete data-set on input-output tables was assembled by the OECD, which started the project in the early 1990's and made the data available (for a limited set of countries) at the beginning of the 2000 's. Han and Schefold (2006) used this data set to compute the wage-profit curves and analyse through a pair-wise comparison of wage-profit curves between countries. Again, they did not compute either the global (i.e., for more than two countries) wage-profit frontier (eq.3.1) or the set of the methods at the frontier, $\mathbf{Z}_{E}^{\mathrm{WPF}}$, as in eq.3.3 above. The same is true for Ozol (1984) and Cekota (1988) who compute the
} 
relative to 63 different combinations of methods of production that stem from the set of methods observed for $2011, \boldsymbol{E}_{2011}^{W P F}$ which are a total of $31^{30}\left(\approx 5.5 \times 10^{44}\right)$.

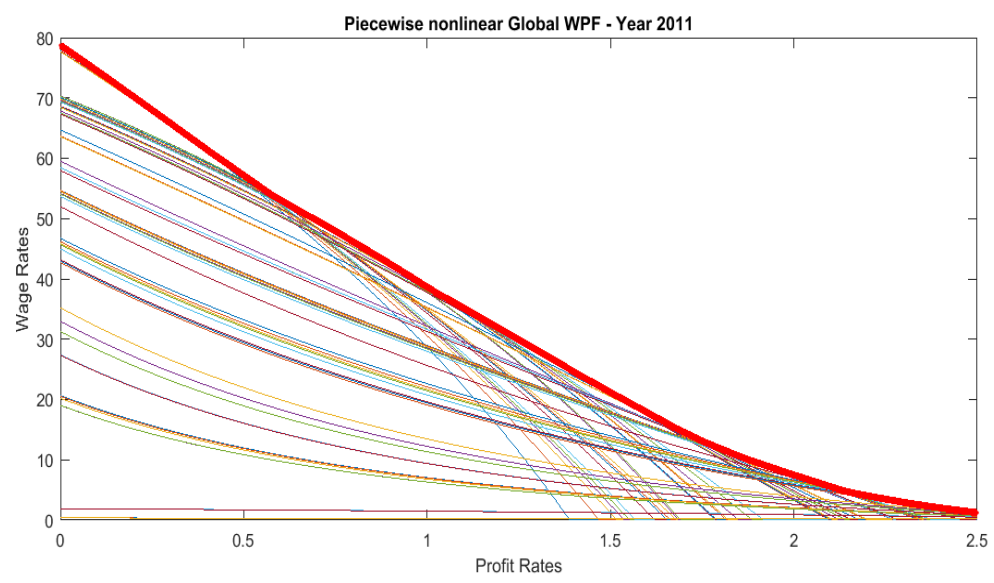

Figure 5.1: Wage-profit frontier 2011, $w_{\boldsymbol{E}_{2011}}^{\mathrm{WPF}}(r, \eta)^{16}$

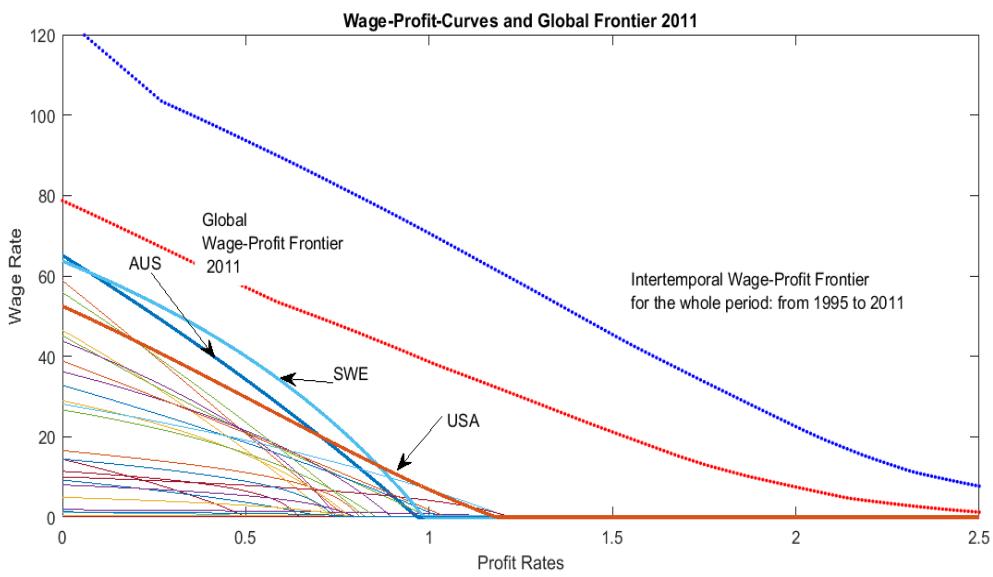

Figure 5.2: Wage-profit frontier, $w_{\boldsymbol{E}_{2011}}^{\mathrm{WPF}}(r, \eta)$, country wage-profit curves relative to 2011 and the inter-temporal wage-profit frontier, $w_{\boldsymbol{\Phi}}^{\mathrm{WPF}}(r, \eta)$

The wage-profit frontier, $w_{\boldsymbol{E}_{2011}}^{\mathrm{WPF}}$ is the most efficient level of the production possible, given the observed sectoral methods of production, $\boldsymbol{E}_{2011}$. It is interesting to see the

wage-profit curves for Canada. Krelle (1977), Ochoa (1989), Shaikh (1988), Mariolis and Tsoulfidis (2011), Shaikh (2012) and Schefold (2013) also compute a few yearly wage-profit curves for USA, but not the wage-profit frontier. Two recent books also compute (randomized) yearly wage-profit curves, Mariolis and Tsoulfidis (2016) and Shaikh (2016).

Clearly, the authors of these contributions did not find the computation of the wage-profit frontier to be an essential ingredient for their investigations. As far as we know this paper is the first that computes the wage-profit frontiers involving a large number of countries and alternative methods.

${ }^{16} w_{\boldsymbol{E}_{2011} \mathrm{WPF}}$ is formed with "pieces" of 63 wage-profit curves, each relative to a combination of methods that belong to 2011 input-output tables of 30 countries. The wage-profit-curves forming the WPF are determined by the set of methods captured in the matrix $\mathbf{Z}_{\boldsymbol{E}_{\boldsymbol{\Phi}}}^{\mathrm{WPF}}$. 
distance between the individual yearly wage-profit curves from the frontier. Figure 5.2 shows the country wage-profit curves, the yearly wage-profit frontier for 2011 and the global inter-temporal wage-profit frontier. The distance between the country wage-profit curves and the wage-profit frontier and among the wage-profit curves themselves could give us valuable information regarding the potential technological growth for these countries. The wage-profit frontier, as discussed earlier, is to be taken as a benchmark since for a given set of methods, it represents the most efficient combination. Hence, it also represents the most efficient level of production possible once the uniform rate of profit, $\bar{r}$, is given. We now define relevant indices to capture the performance of different countries.

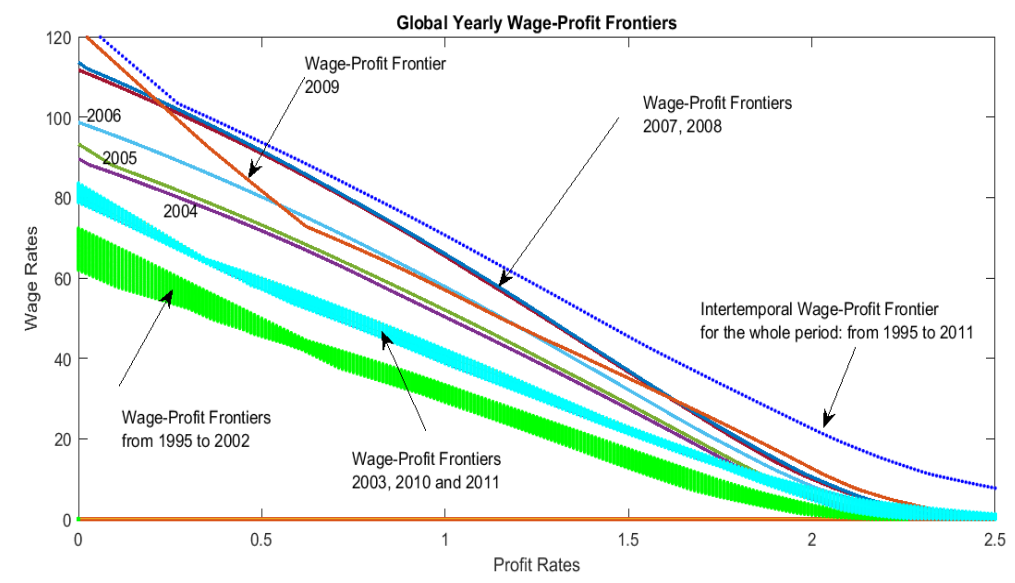

Figure 5.3: Yearly wage-profit frontiers, $w_{\boldsymbol{E}_{1995},}^{W P F} w_{\boldsymbol{E}_{1996}}^{W P F}, \ldots, w_{\boldsymbol{E}_{2011}}^{W P F}$ and the intertemporal wage-profit frontier, $w_{\Phi}^{\text {WPF }}$. The green area includes the wage-profit curves from 1995 to 2002. The cyan area includes the wage-profit curves relative to the years 2003, 2010 and 2011.

Figure 5.3 reports the yearly wage-profit frontiers. We assume that the deflated Input-Output Data may be considered indexes of physical quantities. Therefore, the intertemporal wage-profit frontier is the dominating frontier by definition - it is the most efficient combination of countries' methods because it assembles the methods of the whole period. It is interesting to note the fall associated with the 2010 and 2011 yearly frontiers. The fall is relative to the intertemporal frontier, but also to the preceding years 2008 and 2009. This would indicate that the adoption of best methods or practices has not taken place in these two years. The economic crises which is associated with these years starting from 2008 does not have to be followed by a fall in the wageprofit frontiers. Instead, it should be associated with a fall in activity levels and an increase in unemployment, and not with the adoption of older methods or new but inefficient methods. This problem needs to be investigated further.

\section{The $\mathcal{W} \mathcal{P} \mathcal{C}^{\text {ratio }}$ index}

The measurement of the ratio between the individual wage-profit curves and the wageprofit frontier can give quantitative information on the state of technological progress 
Table 6.1: $\mathcal{W} \mathcal{P} \mathcal{C}^{\text {ratio }}$ index capturing distance to the inter-temporal wage-profit frontier (1995-2011)

\begin{tabular}{|c|c|c|c|c|c|c|c|c|c|c|c|c|c|c|c|c|c|}
\hline Rank & 1995 & 1996 & 1997 & 1998 & 1999 & 2000 & 2001 & 2002 & 2003 & 2004 & 2005 & 2006 & 2007 & 2008 & 2009 & 2010 & 2011 \\
\hline 1 & DN & SWE & sh & DNK & USA & USA & USA & USA & USA & SWE & SWE & sw & SWE & SWE & SWE & SWE & SWE \\
\hline \multirow{2}{*}{ 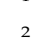 } & $(0.264)$ & $(0.270)$ & (0.258) & (0.254) & $(0.253)$ & $(0.272)$ & (0.272) & $(0.289)$ & (0.312) & $(0.370)$ & (0.370) & $(0.398)$ & $(0.442)$ & $(0.434)$ & (0.369) & $(0.277)$ & $(0.273)$ \\
\hline & SWE & $\begin{array}{l}\text { DNK } \\
\text { DN64 }\end{array}$ & DNK & E & SWE & SWE & DNK & SWE & SWE & USA & USA & USA & GBR & FRA & FRA & USA & AUS \\
\hline \multirow{3}{*}{3} & $(0.245)$ & $(0.264)$ & $(0.243)$ & $(0.248)$ & (0.251) & $(0.222)$ & $(0.217)$ & (0.235) & (0.305) & $(0.327)$ & (0.336) & (0.336) & $(0.338)$ & $(0.342)$ & $(0.362)$ & $(0.244)$ & $(0.250)$ \\
\hline & FRA & FRA & $\begin{array}{l}\text { USA } \\
\text { US? }\end{array}$ & USA & DI & DNK & SWE & $\begin{array}{l}\text { DNK } \\
\text { DN203 }\end{array}$ & DNK & DNK & GBR & GBR & USA & USA & USA & US & SA \\
\hline & $\begin{array}{l}(0.225) \\
\text { NLD }\end{array}$ & $\begin{array}{c}(0.233) \\
\text { DEU }\end{array}$ & $\begin{array}{c}(0.222) \\
\text { FRA }\end{array}$ & $\begin{array}{c}(0.241) \\
\text { FRA }\end{array}$ & $\begin{array}{c}(0.249) \\
\text { FRA }\end{array}$ & $\begin{array}{l}(0.218) \\
\text { GBR }\end{array}$ & $\begin{array}{l}(0.207) \\
\text { GBR }\end{array}$ & $\begin{array}{l}(0.223) \\
G B R\end{array}$ & $\begin{array}{l}(0.277) \\
\text { GBR }\end{array}$ & $(0.315)$ & (0.308) & (0.318) & (0.325) & $(0.320)$ & (0.348) & (0.238) & $(0.221)$ \\
\hline 4 & $(0.216)$ & $(0.214)$ & $(0.210)$ & $(0.214)$ & $(0.215)$ & $(0.201)$ & $\begin{array}{l}\text { GBK } \\
(0.188)\end{array}$ & $\begin{array}{c}\text { GBR } \\
(0.215)\end{array}$ & $\begin{array}{c}\text { GBR } \\
(0.237)\end{array}$ & $\begin{array}{c}\text { FRA } \\
(0.276)\end{array}$ & $\begin{array}{l}\text { DNK } \\
(0.299)\end{array}$ & $\begin{array}{l}\text { DNK } \\
(0.289)\end{array}$ & $\begin{array}{l}\text { FRA } \\
(0298)\end{array}$ & $\begin{array}{l}\text { NLD } \\
(0.302)\end{array}$ & $\begin{array}{l}\text { DNK } \\
(0314)\end{array}$ & $\begin{array}{l}\text { DNK } \\
(0211)\end{array}$ & $\begin{array}{l}\text { FRA } \\
(0.188)\end{array}$ \\
\hline \multirow[t]{2}{*}{5} & DEU & USA & DEU & GBR & GBR & FRA & FRA & FRA & FRA & GBR & FRA & FRA & DNK & (0.302) & AUS & $\begin{array}{c}(0.211) \\
\text { FRA }\end{array}$ & $\begin{array}{l}(0.188) \\
\text { DNK }\end{array}$ \\
\hline & $(0.204)$ & $(0.209)$ & $(0.192)$ & $(0.191)$ & $(0.201)$ & $(0.181)$ & $(0.167)$ & (0.194) & $(0.210)$ & $(0.258)$ & $(0.267)$ & (0.283) & (0.290) & $(0.288)$ & $(0.305)$ & (0.203) & (0.183) \\
\hline \multirow[t]{2}{*}{6} & BEL & NLD & NLD & DEU & DEU & CAN & CAN & DEU & NLD & NLD & NLD & NLD & NLD & GBR & NLD & NLD & CAN \\
\hline & $(0.193)$ & $(0.203)$ & (0.183) & $(0.183)$ & $(0.189)$ & $(0.165)$ & $(0.161)$ & $(0.165)$ & $(0.209)$ & $(0.246)$ & $(0.254)$ & $(0.260)$ & $(0.284)$ & $(0.287)$ & $(0.298)$ & $(0.180)$ & $(0.165)$ \\
\hline \multirow[t]{2}{*}{7} & & & & NL & & NLD & & & AUS & & & & & & & & NLD \\
\hline & $(0.190)$ & $(0.189)$ & (0.171) & $(0.180)$ & (0.183) & (0.163) & $(0.158)$ & (0.164) & (0.196) & $(0.232)$ & $(0.249)$ & $(0.242)$ & $(0.271)$ & $(0.274)$ & $(0.268)$ & (0.177) & (0.154) \\
\hline \multirow[t]{2}{*}{8} & FIN & $\begin{array}{l}\text { AUS } \\
(0169)\end{array}$ & BEL & BEL & $\begin{array}{l}\text { BEL } \\
\text { B. }\end{array}$ & DEU & NI & BEL & II & DI & & & & DNK & & & IRL \\
\hline & $\begin{array}{c}(0.168) \\
\text { GBR }\end{array}$ & $\begin{array}{c}(0.169) \\
\text { FIN }\end{array}$ & $\begin{array}{c}(0.170) \\
\text { AUS }\end{array}$ & $\begin{array}{l}(0.162) \\
\text { AUS }\end{array}$ & $\begin{array}{l}(0.161) \\
\text { CAN }\end{array}$ & (0.155) & $(0.154)$ & (0.161) & $\begin{array}{c}(0.193) \\
\text { BEL }\end{array}$ & (0.230) & (0.247) & $(0.229)$ & (0.265) & $(0.274)$ & (0.264) & $(0.163)$ & (0.153) \\
\hline 9 & $\begin{array}{c}\text { GBR } \\
(0.162)\end{array}$ & $\begin{array}{l}\text { FIN } \\
(0.160)\end{array}$ & $\begin{array}{l}\text { AUS } \\
(0.154)\end{array}$ & $\begin{array}{l}\text { AUS } \\
(0.150)\end{array}$ & $\begin{array}{l}\text { CAN } \\
(0.160)\end{array}$ & $\begin{array}{l}\text { BEL } \\
(0.151)\end{array}$ & $\begin{array}{l}\text { BEL } \\
(0.137)\end{array}$ & $\begin{array}{l}\text { IRL } \\
(0.153)\end{array}$ & $\begin{array}{l}\text { BEL } \\
(0.190)\end{array}$ & $\begin{array}{l}\text { BEL } \\
(0.226)\end{array}$ & $\begin{array}{l}\text { DEU } \\
(0217)\end{array}$ & $\begin{array}{l}\text { BEL } \\
(0.223)\end{array}$ & (0247) & BEL & BEL & GBR & FIN \\
\hline \multirow[t]{2}{*}{10} & AUS & $\begin{array}{l}\text { (0.160) } \\
\text { ITA }\end{array}$ & $\begin{array}{l}\text { (0.154) } \\
\text { FIN }\end{array}$ & $\begin{array}{l}(0.150) \\
\text { ITA }\end{array}$ & $\begin{array}{l}(0.160) \\
\text { AUS }\end{array}$ & (0.151) & $\begin{array}{c}(0.137) \\
\text { AUS }\end{array}$ & CAN & $\begin{array}{c}\text { (0.190) } \\
\text { DEU }\end{array}$ & $\begin{array}{l}\text { (0.226) } \\
\text { IRL }\end{array}$ & (0.217) & $\begin{array}{c}\text { (0.223) } \\
\text { DEU }\end{array}$ & $\begin{array}{c}(0.247) \\
\text { BEL }\end{array}$ & $\begin{array}{c}(0.263) \\
\text { FIN }\end{array}$ & $\begin{array}{c}\text { (0.258) } \\
\text { IRL }\end{array}$ & $\begin{array}{l}(0.154) \\
\text { FIN }\end{array}$ & $\begin{array}{c}(0.146) \\
\text { BEL }\end{array}$ \\
\hline & $(0.151)$ & $(0.157)$ & $(0.153)$ & $(0.148)$ & $(0.160)$ & $(0.150)$ & $(0.137)$ & $(0.151)$ & $(0.187)$ & $(0.213)$ & $(0.214)$ & $(0.214)$ & $(0.242)$ & $(0.259)$ & $(0.251)$ & (0.152) & (0.145) \\
\hline \multirow[t]{2}{*}{11} & CAN & GBR & IRL & FIN & ITA & FIN & IRL & FIN & CAN & CAN & FIN & FIN & DEU & DEU & GBR & DEU & GBR \\
\hline & & $\begin{array}{l}(0.156) \\
\text { FEP }\end{array}$ & & & & $(0.1)$ & (0.13 & (o. & (0.1 & $(0.20$ & $(0.1$ & & $(0.231)$ & $(0.254)$ & $(0.236)$ & (0.139) & \\
\hline \multirow[t]{2}{*}{12} & ITA & $\begin{array}{l}\text { ESP } \\
\text { ES151) }\end{array}$ & ITA & CAN & FIN & IRL & FIN & AUS & FIN & FIN & ITA & ITA & ITA & ITA & DEU & IRL & DEU \\
\hline & $\left(\begin{array}{c}0.141) \\
\mathrm{FSP}\end{array}\right.$ & (0.151) & $(0.146)$ & $(0.144)$ & (0.143) & (0.132) & (0.136) & (0.138) & (0.176) & $(0.195)$ & (0.176) & (0.176) & $\left(\begin{array}{c}0.191) \\
\text { FSP }\end{array}\right.$ & $\begin{array}{l}(0.205) \\
\text { FSP }\end{array}$ & (0.233) & (0.132) & $(0.134)$ \\
\hline \multirow[t]{2}{*}{13} & ESP & IRL & CA & IR & IRL & JPN & IT & ITA & ITA & ITA & & & & & & & \\
\hline & $(0.137)$ & $(0.151)$ & $\begin{array}{c}(0.140) \\
\text { FSP }\end{array}$ & $\begin{array}{c}(0.143) \\
\text { FSP }\end{array}$ & (0.141) & $(0.129)$ & $(0.119)$ & $(0.124)$ & (0.148) & (0.177) & $\begin{array}{l}(0.165) \\
\left(x^{2}\right)\end{array}$ & (0.162) & (0.178) & (0.194) & (0.199) & $(0.117)$ & $(0.108)$ \\
\hline 14 & & CAN & & & & & & & & & & & & & & & \\
\hline & $(0.136)$ & $(0.145)$ & $(0.136)$ & $(0.133)$ & $(0.131)$ & $(0.129)$ & $(0.1$ & $(0.122)$ & $(0.138)$ & $(0.149)$ & $(0.138)$ & & & & & & $(0.107)$ \\
\hline 15 & $\mathrm{AL}$ & $\mathrm{AU}$ & $\mathrm{AU}$ & $\mathrm{AU}$ & & ESP & ESI & ESP & JPI & $\mathrm{AU}$ & AUT & A & & A & TT & & AUT \\
\hline & $(0.132)$ & $(0.120)$ & $(0.102)$ & $(0.105)$ & $(0.126)$ & $(0.111)$ & $(0.106)$ & (0.115) & $(0.1$ & & & & & $(0)$. & & & $(0.069)$ \\
\hline 16 & JPN & $\mathrm{JPN}$ & JPN & JPN & AUT & AUT & AUT & AUT & AUT & GRC & GRC & GRC & GRC & GRC & GRC & GRC & TWN \\
\hline & $(0.128)$ & (0.115) & (0.0 & $(0.101)$ & $(0.103)$ & $(0.086)$ & $(0.078)$ & $(0.082)$ & (0.098) & $(0.097)$ & $(0.094)$ & $(0.098)$ & $(0.101)$ & $(0.111)$ & $(0.109)$ & $(0.062)$ & $(0.056)$ \\
\hline 17 & GR & GF & Th & & Th & Th & Th & TWN & & $\mathrm{JP}$ & TWN & & & & & & GRC \\
\hline & $(0.072)$ & $(0.072)$ & $(0.070)$ & $(0.065)$ & $(0.067)$ & $(0.070)$ & $(0.0$ & $(0.074)$ & $(0.073)$ & $(0.082)$ & $(0.068)$ & $(0.075)$ & $(0.6$ & $(0.080)$ & & & $(0.056)$ \\
\hline 18 & TWN & TWN & GRC & TW & GRC & GI & & GI & & & & & & & & & \\
\hline & (0.0 & (O.0) & (0.0 & $(0.0$ & (0.0 & (0.0 & (0.0 & $(0.0$ & & $(0.6)$ & & & & & & & $(0.042)$ \\
\hline 19 & KOR & KOR & KOR & PI & $\begin{array}{l}\text { PRT } \\
\text { PRO }\end{array}$ & KOR & & & KOR & & & & & & & & CZE \\
\hline & $(0.059)$ & $(0.062)$ & (0.058) & (0.043) & (0.046) & (0.048) & $(0.044)$ & (0.046) & (0.049) & (0.056) & $(0.051)$ & (0.055) & $(0.060)$ & $(0.064)$ & 062) & (0.038) & $(0.035)$ \\
\hline 20 & $\begin{array}{l}\text { PRT } \\
\text { PRT }\end{array}$ & $\begin{array}{l}\text { PRT } \\
\text { PRT }\end{array}$ & & KOR & KOR & & & & & & $\begin{array}{l}\text { PRT } \\
\text { PRT }\end{array}$ & & & & & & PRT \\
\hline & $(0.052)$ & $(0.053)$ & $(0.044)$ & $(0.035)$ & $(0.044)$ & (0.034) & $(0.032)$ & $(0.037)$ & $(0.044)$ & $(0.052)$ & $(0.050)$ & $(0.049)$ & $(0.051)$ & $(0.061)$ & $(0.058)$ & $(0.033)$ & $(0.033)$ \\
\hline 21 & CZE & $C Z$ & CZF & $C Z E$ & $C 2$ & $C Z$ & CZE & $\mathrm{C}$ & $C Z$ & & & HUN & $\mathrm{HU}$ & & $\mathrm{KOF}$ & IUN & UN \\
\hline 22 & $\begin{array}{c}\text { (0.028) } \\
\text { TUR }\end{array}$ & $\begin{array}{l}(0.028) \\
\text { HUN }\end{array}$ & & & & & & & & & & & & & & & \\
\hline & (0.027) & (0.021) & HL & $\begin{array}{l}\mathrm{H} \\
{ }_{0}\end{array}$ & $\begin{array}{l}\text { HUN } \\
(0.016)\end{array}$ & HL & & HUN & & C & $\mathrm{P}$ & & & & & & POL \\
\hline 23 & & & & $\mathrm{BI}$ & $\mathrm{MI}$ & (0.0 & POL & $\mathrm{POL}$ & (0.0 & $\begin{array}{c}(0.042) \\
\mathrm{POL}\end{array}$ & $\begin{array}{l}(0.024) \\
\text { MEX }\end{array}$ & $(0.025)$ & & $(0.032)$ & & & $(0.019)$ \\
\hline & & $(0,8)$ & & & & & & & & (0. & & & & & & & \\
\hline 24 & & & & & & & & & & & & & & & & & \\
\hline & $\begin{array}{l}\text { MII } \\
(0.01\end{array}$ & 00 & & & & & & & & & & & & & & & \\
\hline 25 & & & & & & & & & & & & & & & & & \\
\hline & $(0.016)$ & $(0.0$ & $(0.0$ & & $(0.0$ & & & & & & & & & & & & \\
\hline 26 & BRA & MEX & TUI & TU & TUR & CHN & $\mathrm{CH}$ & CHN & CHN & $\mathrm{CH}$ & IN & ID & IN & IND & IND & IDN & $\begin{array}{l}\text { IDN } \\
\text { IDN }\end{array}$ \\
\hline & $(0.016)$ & (0.014) & $(0.00$ & $(0.00$ & (0.0 & $(0.0$ & $(0.002)$ & (0.0 & (0.0 & $(0.003)$ & $(0.002)$ & $(0.002)$ & $(0.002)$ & $(0.002)$ & $(0.002)$ & $(0.002)$ & $(0.002)$ \\
\hline 27 & RUS & $\mathrm{RU}$ & RU & $\mathrm{RL}$ & $\mathrm{CF}$ & ID & IN & IN & & ID & ID & & & ID & IDN & IND & IND \\
\hline & & & & & & & & $(0.0$ & & (0. & $(0.6$ & (0. & (0. & (0. & (0. & (0. & $(0.002)$ \\
\hline 28 & ID & ID & & & & & & & & & & & & & & & TUR \\
\hline & & & & & & & & & & & & & & & & (0. & $(0.001)$ \\
\hline 29 & IND & IN & & & & & & & & & & & & & & & \\
\hline & & & & & & & & & & & & & & & & & (0.000) \\
\hline 30 & $\begin{array}{l}\text { CHN } \\
(0.002)\end{array}$ & $\begin{array}{c}\text { CHN } \\
(0.002)\end{array}$ & $\begin{array}{l}\text { CHN } \\
(0.002)\end{array}$ & $\begin{array}{l}\text { IDN } \\
(0.001)\end{array}$ & $\begin{array}{c}\text { RUS } \\
(0.001)\end{array}$ & $\begin{array}{l}\text { RUS } \\
(0.001)\end{array}$ & $\begin{array}{c}\text { RUS } \\
(0.001)\end{array}$ & $\begin{array}{c}\text { RUS } \\
(0.001)\end{array}$ & $\begin{array}{l}\text { RUS } \\
(0.001)\end{array}$ & $\begin{array}{c}\text { RUS } \\
(0.001)\end{array}$ & $\begin{array}{c}\text { JPN } \\
(0.000)\end{array}$ & $\begin{array}{c}\text { JPN } \\
(0.000)\end{array}$ & $\begin{array}{c}\text { JPN } \\
(0.000)\end{array}$ & $\begin{array}{c}\text { JPN } \\
(0.000)\end{array}$ & $\begin{array}{c}\text { JPN } \\
(0.000)\end{array}$ & $\begin{array}{c}\text { JPN } \\
(0.000)\end{array}$ & $\begin{array}{l}\text { JPN } \\
(0.000)\end{array}$ \\
\hline
\end{tabular}


and productive capacity of a national system of innovation as a whole. When the systems are viewed as being autarkic, it is possible that some may be very advanced in certain sectors, but they may not be in a position to generate high values on the whole. On the other hand, a high wage-profit curve (or low distance to the wage-profit frontier) has to be unambiguously associated with an efficient system with a potential to generate high values, i.e., high purchasing power.

We propose a simple index of country performance in terms of distance to the frontier. Given a set of systems $\boldsymbol{E}$, (derived from combinations of the available methods, $\boldsymbol{\Phi )}$, the $\mathcal{W} \mathcal{P} \mathcal{C}^{\text {ratio }}$ index provides a measure of the distance of the individual wage profit curves (or frontiers) with respect to the frontier which we use as benchmark. For the $j$ th country, at time $t$, the $\mathcal{W} \mathcal{P} \mathcal{C}^{\text {ratio }}$ index is computed as:

$$
\mathcal{W P C}_{j, t}^{\text {ratio }}=\frac{1}{m} \sum_{i=1}^{m} \frac{w_{j, t}\left(r_{i}, \eta\right)}{w_{\boldsymbol{E}_{t}}^{\mathrm{WPF}}\left(r_{i}, \eta\right)}
$$

where:

- $j=1,2, \ldots, N$ (number of countries), $t=1,2, \ldots, T$ (number of years),

- $m$ is the number of points that belong to the domain of the reference wage-profit frontier $w_{\boldsymbol{E}_{t}}^{\mathrm{WPF}}\left(r_{i}, \eta\right)^{17}$.

- $r_{i}=\left\{0 \leq r_{i} \leq r_{m}=\mathcal{R}_{\boldsymbol{E}_{t}}^{\mathrm{WPF}}\right\}, i=1, \ldots, m$;

- $\mathcal{R}_{\boldsymbol{E}_{t}}^{\mathrm{WPF}}$ is the maximum rate of profit of $w_{\boldsymbol{E}_{t}}^{\mathrm{WPF}}\left(r_{i}, \eta\right)$.

The value of the index lies between 0 and 1. The wage-profit frontier is the most efficient with respect to all possible combinations of methods that belong to $\boldsymbol{E}_{t}$. Clearly, for any $r_{i}$, the relation $w_{\boldsymbol{E}_{t}}^{\mathrm{WPF}}\left(r_{i}, \eta\right) \geq w_{j, t}\left(r_{i}, \eta\right)$ always holds. For case in which the value of the index equals to 1 , the respective country is dominant with respect to all the other countries. It is dominant in all the sectors, for the whole domain of the wageprofit frontier and for any profit rate. In this case, the country wage-profit curve and the wage-profit frontier would overlap, i.e. $w_{\boldsymbol{E}_{t}}^{\mathrm{WPF}}\left(r_{i}, \eta\right)=w_{j, t}\left(r_{i}, \eta\right)$. However, a low ratio does not necessarily mean that a country is not efficient as a productive system. This is because the index $\mathcal{W} \mathcal{P} \mathcal{C}_{j, \boldsymbol{E}_{t}}^{\text {ratio }}$ captures the vicinity of country $j$ wage-profit curve with respect to the wage-profit frontier (here the inter-temporal wage-profit frontier, $w_{\Phi}^{W P F}$ ).

The distance of a wage-profit curve to the wage-profit frontier indicates the potential capacity of that system to generate a higher purchasing power. High values of $\mathcal{W} \mathcal{P} \mathcal{C}_{j, \boldsymbol{E}_{t}}^{\text {ratio }}$ indicate a harmonious combination of the methods of production. On the other hand, a low values may indicate an incongruous combination of the methods of production or, alternatively, inefficient methods on the whole. The term 'harmonious' here refers to a balanced distribution of production. High values of $\mathcal{W} \mathcal{P} \mathcal{C}_{j, \boldsymbol{E}_{t}}^{\text {ratio }}$ index would indicate high performance for all the industries. But as we pointed out earlier, a

\footnotetext{
${ }^{17}$ The domain of the wage-profit curves and of the wage-profit frontier is composed of points separated by a step size $h$ (see the Appendix).
} 
low level of the $\mathcal{W} \mathcal{P} \mathcal{C}_{j, E_{t}}^{\text {ratio }}$ may be associated with either low performance in all sectors or low performance in only a few sectors. The totally non-harmonious case is the one relative to a non viable system.

Japan provides an interesting case that merits discussion at this point. For the period going from 1995-2004, Japan has relative low levels of the $\mathcal{W} \mathcal{P} \mathcal{C}_{j, \boldsymbol{E}_{t}}^{\text {ratio }}$ index, see table 6.1 and for the period 2005-2011, Japan has value zero because the combination of methods is not viable. This phenomena can be explained by the fact that Japan, for the methods used during 2005-2011, is bound to be dependent on imports ${ }^{18}$. But we will see shortly that Japan generally has a very high value of the total Net National Productivity (measured with yearly production prices) because some of the sectors in Japan happen to be very advanced.

The index is useful when we attempt compare different wage-profit frontiers computed using a subset of the methods that go in to the construction of the global intertemporal wage-profit frontier, i.e. the benchmark, $w_{\boldsymbol{\Phi}}^{\text {WPF }}(r, \eta)$. This is relevant when we calculate the value of the $\mathcal{W} \mathcal{P} \mathcal{C}^{\text {ratio }}$ index using the yearly wage-profit frontiers, $w_{\boldsymbol{E}_{1995}^{\mathrm{WPF}}}^{\mathrm{W}}$ $w_{\boldsymbol{E}_{1996}}^{\mathrm{WPF}}, \ldots, w_{\boldsymbol{E}_{2011}}^{\mathrm{WPF}}$, and the benchmark inter-temporal wage-profit frontier, $w_{\boldsymbol{\Phi}}^{\mathrm{WPF}}(r, \eta)$.As we have pointed out from Figure 5.3 we can see that the yearly wage-profit frontiers move towards the North-East corner, which indicates technological growth for the period going from 2002 to 2007-2008. By computing the value of the $\mathcal{W P}_{\mathcal{P}}{ }^{\text {ratio }}$, we can provide a numerical measure to this pattern. Figure 6.1 shows the value of the $\mathcal{W} \mathcal{P C}^{\text {ratio }}$.

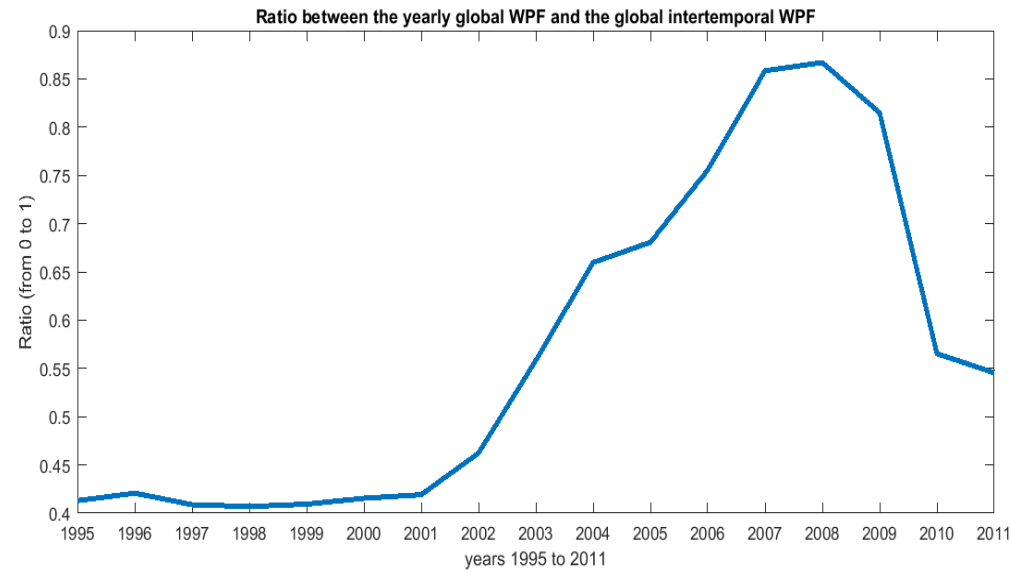

Figure 6.1: The values of $\mathcal{W P C}{ }^{\text {ratio }}$ considering yearly wage-profit frontiers, $w_{\boldsymbol{E}_{1995}}^{W P F}, w_{\boldsymbol{E}_{1996}}^{W P F}, \ldots, w_{\boldsymbol{E}_{2011}}^{W P F}$, and inter-temporal wage-profit frontier,
$w_{\boldsymbol{\Phi}}^{W P F}$.

\footnotetext{
${ }^{18}$ To be more precise, several countries in our dataset would have some sectors that produce less than what is actually necessary for the whole system to carry on production. Consequently, the produced social surplus for these sectors is negative.
} 


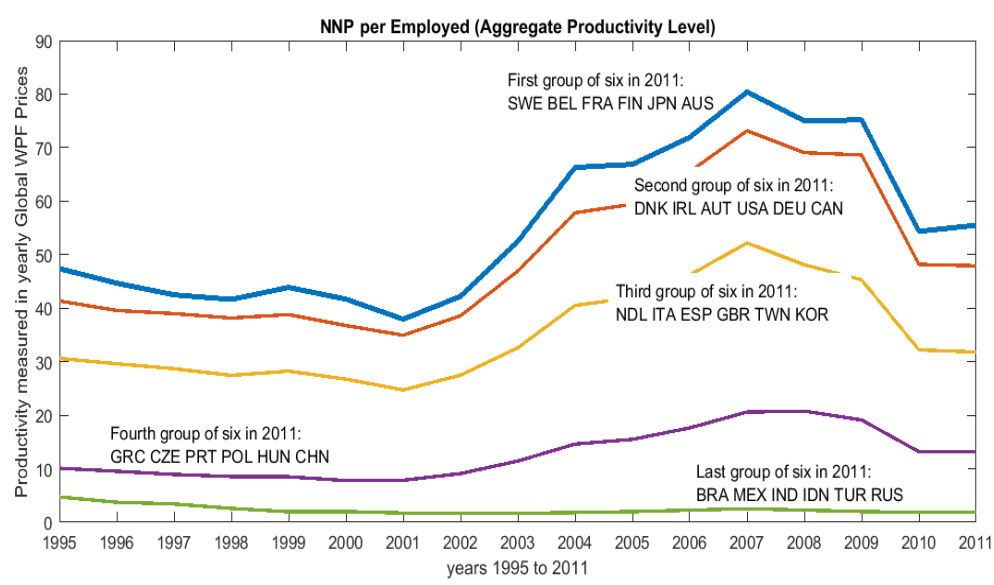

Figure 6.2: Net National Product per employed. The figure shows the average values grouped according to the positions in 2011. The values are in terms of the average production prices of the yearly wage-profit frontiers, all measured with the same numéraire, $\eta$

\section{The Sectoral Technological Progress Index $(\mathcal{S T} \mathcal{P}$-index $)$}

We noted earlier that each wage-profit frontier $w_{\boldsymbol{E}}^{W P F}(r, \eta)$ is piecemeal function formed by a total of $v$ wage-profit curves, where there is a specific set of methods associated with each interval. We know from Bharadwaj (1970)) that the intervals forming the wage-profit frontier and hence the switch points (eq.3.2) are invariant with respect to the chosen numéraire. This also implies that the combinations at the frontier, given by $\mathbf{Z}_{E}^{\mathrm{WPF}}$ (eq.3.3), are invariant with respect to the numéraire. Thus the information embedded in the entries of $\mathbf{Z}_{\boldsymbol{E}}^{\mathrm{WPF}}$ identify the most efficient production methods, i.e., those that contribute to the formation of the wage-profit frontier. A country that "adopts" these methods would be highly efficient and advanced in terms of its production. Its wage-profit curves would be contributing to the formation of the wage-profit frontier (for example one of the curves as in fig. 5.1). But looking at Figure 5.2 or the low values reported in Table $6.1\left(\mathcal{W} \mathcal{P} \mathcal{C}^{\text {ratio }}\right)$ indicates that the individual countries are far from adopting the set of methods associated with the wage-profit frontier.

We construct a numéraire-free index of performance which does not depend on prices, but exclusively on the contributions to the wage-profit frontier. We believe that this would be a robust measure of technological progress. We call this index Sectoral Technological Progress, $\mathcal{S} \mathcal{T} \mathcal{P}-$ index, when we consider the technological progress at the industry level and at the index at the national level is called Technological Progress, $\mathcal{T} \mathcal{P}-$ index

The methods of production contributing to the formation of the wage-profit frontier are first weighted according to their contribution. A method that would contribute to the formation of the wage-profit frontier for the entire domain (i.e., all intervals), $r \in\left[0, \mathcal{R}_{\boldsymbol{E}_{t}}^{\mathrm{WPF}}\right]$ it is given a value 1 . But if it contributes only for some intervals and not for others, it would be weighted according to the length of the intervals for which 
Table 7.1: $\mathcal{S T} \mathcal{P}$-index. Country Ranks for Technical Progress at the Sectoral Level

\begin{tabular}{|c|c|c|c|c|c|c|c|c|c|c|c|c|c|c|c|c|c|}
\hline Sectors & 1995 & 1996 & 1997 & 1998 & 1999 & 2000 & 2001 & 2002 & 2003 & 2004 & 2005 & 2006 & 2007 & 2008 & 2009 & 2010 & 2011 \\
\hline Agriculture, Hunting, Forestry and Fishing & SWE & SWE & SWE & SWE & SWE & USA & USA & USA & SWE & SWE & SWE & SWE & SWE & SWE & SWE & SWE & AUS \\
\hline Mining and Quarrying & NLD & NLD & NLD & DNK & DNK & NLD & NLD & NLD & NLD & NLD & NLD & NLD & NDD & NLD & TWN & TWN & NLD \\
\hline Food, Beverageses and Tobacco & JPN & JPN & JPN & JPN & JPN & JPN & JPN & JPN & FIN & FIN & FN & IRL & $\mathbb{R L}$ & IRL & FIN & $\mathbb{R L}$ & IRL \\
\hline Textiles and Textile Products & NLD & BEL & DNK & DNK & DNK & GBR & GBR & GBR & GBR & GBR & ERA & GBR & FRA & FRA & FRA & FRA & FRA \\
\hline Leather, Leather and Footwear & SWE & GBR & DNK & DNK & DNK & DNK & GBR & GBR & GBR & GBR & GBR & IRL & $\mathbb{R L}$ & IRL & $\mathbb{R L}$ & IRL & IRL \\
\hline Wood and Products of Wood and Cork & DNK & AUS & AUS & DNK & DNK & CAN & CAN & CAN & FRA & FRA & FRA & FRA & CAN & CAN & BEL & SWE & SWE \\
\hline Pulp, Paper, Paper, Printing and Publishing & FIN & SWE & FIN & FIN & $\mathbb{R L}$ & IRL & $\mathbb{R L}$ & FIN & IRL & IRL & IRL & IRL & $\mathbb{R L}$ & IRL & $\mathbb{R L}$ & $\mathbb{R L}$ & $\mathbb{R L}$ \\
\hline Coke, Refined Petroleum and Nuclear Fuel & JPN & TWN & TWN & TWN & TWN & TWN & TWN & TWN & TWN & TWN & TWN & TWN & TWN & TWN & TWN & TWN & TWN \\
\hline Chemicals and Chemical Products & $\mathbb{R} L$ & IRL & $\mathbb{R L}$ & IRL & $\mathbb{R R}$ & IRL & IRL & IRL & IRL & IRL & SWE & IRL & $\mathbb{R L}$ & IRL & $\mathbb{R R}$ & IRL & IRL \\
\hline Rubber and Plastics & BEL & BEL & DNK & AUT & DNK & USA & USA & BEL & FRA & FRA & FRA & FRA & FRA & FRA & FRA & FRA & FRA \\
\hline her Non-MetallicI & IRL & AUT & AUT & DEU & JPN & JPN & JPN & JPN & JPN & AUS & AUS & AUS & AUS & AUS & AUS & AUS & AUS \\
\hline Basic Metals and Fabricated Metal & AUS & AUS & AUS & AUS & CAN & CAN & CAN & USA & USA & GBR & GBR & CAN & CAN & CAN & AUS & AUS & AUS \\
\hline Machinery, Nec & DNK & JPN & JPN & JPN & JPN & JPN & JPN & JPN & JPN & JPN & JPN & JPN & JPN & FRA & JPN & JPN & JPN \\
\hline Electrical and Optical Equipment & AUT & SWE & SWE & SWE & USA & USA & USA & USA & FIN & SWE & USA & USA & USA & USA & USA & USA & USA \\
\hline Transport Equipment & DEU & PRT & PRT & PRT & PRT & SWE & NLD & JPN & DNK & SWE & SWE & IRL & $\mathbb{R L}$ & IRL & BEL & AUS & AUS \\
\hline Manufacturing, Nec; Recycling & $\mathbb{R} L$ & IRL & $\mathbb{R L}$ & GBR & JPN & JPN & JPN & JPN & JPN & IRL & IRL & IRL & $\mathbb{R L}$ & IRL & $\mathbb{R L}$ & IRL & $\mathbb{R} L$ \\
\hline nd Water Supply & USA & CAN & CAN & CAN & TWN & CAN & TWN & TWN & TWN & TWN & TWN & TWN & TWN & TWN & CAN & TWN & TWN \\
\hline Construction & AUT & AUT & SWE & AUT & JPN & JPN & JPN & JPN & AUT & AUT & AUT & DEU & DEU & DEU & DEU & DEU & DEU \\
\hline Sale, Maintenance and Repair & JPN & SWE & SWE & USA & USA & USA & USA & USA & USA & USA & USA & USA & USA & USA & USA & USA & USA \\
\hline Wholesale Trade and Commission Trade, Excep & JPN & USA & USA & USA & USA & USA & USA & USA & USA & USA & USA & USA & USA & USA & USA & USA & USA \\
\hline Retail Trade, Except of Motor Vehicles and Motorcycles; Repair of Household Goods & JPN & SWE & SWE & SWE & SWE & USA & USA & USA & SWE & SWE & SWE & SWE & SWE & SWE & SWE & SWE & SWE \\
\hline tolc and Rectarunt & AUT & AUT & ITA & FRA & FRA & ITA & FRA & FRA & FRA & FRA & AUT & AUT & AUT & FRA & ITA & AUT & AUT \\
\hline Inland Transport & FIN & FIN & FIN & FIN & $\mathrm{FIN}$ & USA & USA & ITA & ITA & ITA & ITA & ITA & ITA & ITA & ITA & ITA & ITA \\
\hline Water Transport & JPN & DEU & DEU & DEU & TWN & TWN & TWN & TWN & DEU & DEU & GRC & GRC & GRC & GRC & GRC & GRC & GRC \\
\hline Air Transport & JPN & JPN & JPN & JPN & JPN & JPN & JPN & JPN & JPN & GRC & GRC & FIN & GRC & CZE & HUN & USA & USA \\
\hline Other Supporting and Auxiliary Transport Activitie & JPN & JPN & AUS & FIN & FIN & JPN & JPN & JPN & JPN & JPN & JPN & USA & USA & USA & JPN & $\mathrm{JPN}$ & JPN \\
\hline Post and Telecommunications & JPN & JPN & JPN & JPN & TWN & TWN & TWN & TWN & TWN & TWN & TWN & GRC & GRC & GRC & GRC & GRC & GRC \\
\hline Financial Intermediation & JPN & SWE & SWE & SWE & FIN & JPN & JPN & PRT & PRT & PRT & PRT & PRT & PRT & PRT & AUT & DNK & DNK \\
\hline Real Estate Activities & ITA & ITA & ITA & ITA & ITA & ITA & ITA & ITA & GRC & GRC & GRC & GRC & GRC & GRC & ITA & ITA & ITA \\
\hline Renting of $M$ & DEU & DEU & DEU & DEU & GBR & GBR & USA & USA & GBR & GBR & GBR & GBR & GBR & GBR & JPN & $\mathrm{JPN}$ & JPN \\
\hline Other Community, Social and Personal Services & DNK & DNK & DNK & DNK & DNK & JPN & JPN & JPN & JPN & JPN & JPN & JPN & FIN & FN & JPN & JPN & JPN \\
\hline
\end{tabular}


it contributes. This is done for all the methods associated with production in each industry. As an example let us take the wage-profit frontier for 2011, $w_{\boldsymbol{E}_{2011}}^{\mathrm{WPF}}(r, \eta)$, as reported in Fig. 5.1. The frontier for 2011 is formed by 63 intervals. Each interval will be associated with a specific combination of methods, $\mathbf{z}$, i.e. a triple $\left(\mathbf{A}^{\mathbf{z}}, \mathbf{L}^{\mathbf{z}}, \mathbf{B}^{\mathbf{z}}\right)$. The length of the domain of the wage-profit frontier, $r \in\left[0, \mathcal{R}_{\boldsymbol{E}_{2011}^{\mathrm{WPF}}}\right]$ (see eq. 3.2), is normalized to one. The weight of the contribution to the methods will be proportional to the length of the interval for which these methods belong to the efficient combination, i.e. the triple $\left(\mathbf{A}^{\mathbf{z}}, \mathbf{L}^{\mathbf{z}}, \mathbf{B}^{\mathbf{z}}\right)$. In short, if a given method $z_{i}$ belongs to all the set of methods contributing to the formation of $w_{\boldsymbol{E}_{2011}}^{\mathrm{WPF}}(r, \eta)$, it will be associated with value 1 . Else it will be given a value proportional to the intervals in which it contributes. All the other methods in $\Phi$ that never contribute to $w_{\boldsymbol{E}_{2011}}^{\mathrm{WPF}}(r, \eta)$ are given value 0 .

If the methods belonging to the frontier are implemented by some country, it will be considered as being economically efficient in its production and also indicates technological progress. However, this leadership may not be exclusive for a good $i$ and a country might be a leader only for some intervals and not for others. Hence, the leadership position may have to be shared with other countries which also contribute to other intervals of the frontier. Furthermore, there may be methods that not enter the frontier which might be almost as good as the winning methods.

In order to account for those methods that are not the "most efficient", but are "almost as efficient", we use a scheme in which the methods used for the production of good $i$ can be ordered as being first, second, third, ... and last $\left(N^{t h}\right)$. For a given interval and a given good $i$, a method is ranked as first if it belongs to the frontier combination of methods. We remove this winning method from the original set of methods and recompute the new wage-profit frontier. The method that would substitute the winning method and emerge on the top would be ranked second. We remove the second method and repeat the process to determine the third by computing a new (sub-efficient) wage-profit frontier. And so on.

For each country $j$, we can summarize this information in terms of a matrix $\mathbf{V}_{\boldsymbol{E}_{t}}^{j}$ :

$$
\mathbf{V}_{\boldsymbol{E}_{t}}^{j}=\left\{v_{i q}^{j}\right\}=\left[\begin{array}{cccc}
v_{11}^{j} & v_{12}^{j} & \ldots & v_{1 N}^{j} \\
v_{21}^{j} & v_{22}^{j} & \ldots & v_{2 N}^{j} \\
\vdots & \vdots & v_{i q}^{j} & \vdots \\
v_{n 1}^{j} & v_{n 2}^{j} & \ldots & v_{n N}^{j}
\end{array}\right] ;
$$

where: $j=1,2, \ldots, N$ are the countries; $i=1,2, \ldots, n$ are the sectors or industry and $q=1,2, \ldots, N$ is the relative position ${ }^{19}$.

The value $v_{i q}^{j}$ is the weighted contribution that country $j^{\prime}$ s method $i$ to the formation of the wage-profit frontier, once the superior methods $q-1$ of all the countries have been removed form the total set of methods in $\boldsymbol{E}_{t}$. When the method of country $j$ to produce good $i$ does not enter in the $q^{\text {th }}$ position, $v_{i q}^{j}$ would be 0 . This could mean

\footnotetext{
${ }^{19}$ The number of positions (first , second, ..., last) is the same as the number of countries.
} 
either that the method of production for good $i$ of country $j$ has already been removed because it was superior or it is yet to be competitive. In the former case, there are some values $v_{i 1}^{j}, v_{i 2}^{j}, \ldots, v_{i(q-1)}^{j}$ going from 1 to $(q-1)$ that are greater than 0 . In the latter case, it indicates that positive values are going to be associated with lower positions, hence some of the values $v_{i(q+1)}^{j}, v_{i(q+2)}^{j}, \ldots, v_{i N}^{j}$ should be greater than 0 . If $v_{i q}^{j}=1$, it indicates that for the $q^{\text {th }}$ position, the production method of good $i$ of country $j$ is entering in all the intervals forming the wage-profit frontier to be associated with position $q$.

The Country Sectoral Contribution of Innovation, matrix $\mathbf{V}_{\boldsymbol{E}_{t^{\prime}}}^{j}$ is important because it provides a robust assessment of technological progress of a country with respect to a particular sector or industry $i$. But it also provides information regarding the state of technological progress of national system as a whole. An advanced country would have positive values for most of the first columns, while the others would be populated by 0 values. The converse would apply for a least developed country. Furthermore an "unbalanced" country would have values scattered across sectors.

In this case, it is clear that a weighted sum by columns of the values of $\mathbf{V}_{\boldsymbol{E}_{t}}^{j}$ could provide an additional information. The first values (first columns) ought to have the highest weight and decreases as the membership goes down. There are many possible weighting functions that one can make use of. We have chosen a weighting function with decreasing linear weights $\omega=[1,1-1 / N, 1-2 / N, \ldots, 1-(N-1) / N]^{\prime}$.

The resulting value provides a measurement of sectoral technological progress, $\mathcal{S} \mathcal{T} \mathcal{P}_{\boldsymbol{E}_{t}}$ for country $j$ :

$$
\mathcal{S} \mathcal{T}_{\boldsymbol{P}_{t}}^{j}=\mathbf{V}_{\boldsymbol{E}_{t}}^{j} \boldsymbol{\omega}=\left[\begin{array}{c}
t p_{1}^{j} \\
t p_{2}^{j} \\
\vdots \\
\vdots \\
t p_{n}^{j}
\end{array}\right]=\left[\begin{array}{cccc}
v_{11}^{j} & v_{12}^{j} & \cdots & v_{1 N}^{j} \\
v_{21}^{j} & v_{22}^{j} & \cdots & v_{2 N}^{j} \\
\vdots & \vdots & v_{i q}^{j} & \vdots \\
\vdots & \vdots & \vdots & v_{(n-1) N}^{j} \\
v_{n 1}^{j} & v_{n 2}^{j} & \cdots & v_{n N}^{j}
\end{array}\right]\left[\begin{array}{c}
1 \\
1-\frac{1}{N} \\
1-\frac{2}{N} \\
\vdots \\
1-\frac{N-1}{N}
\end{array}\right]
$$

Value 1 means that country $j$ has undisputed or unambiguous technological progress, for the production of commodity $i$, i.e. Methods of country $j$ contribute to the whole domain of the wage-profit frontier. Lower values indicate relative backwardness, - i.e. that the method of country $j$ would be relevant only in the absence of those methods with higher values. Value $1 / N$ is the lowest because it means total backwardness ${ }^{20}$, i.e. it is a method that is always inferior relative to the other $(N-1)$ methods. Table 7.1 reports the sectoral leadership, i.e., countries obtaining first positions (winners) for different sectors. This information helps us to assess technological dominance and temporal changes. For reasons of space, we are not presenting the data on the values and the countries occupying the $2^{n d}, 3^{r d}, \ldots, N^{\text {th }}$ positions.

\footnotetext{
${ }^{20}$ This is of course relative to the set of countries that are considered.
} 


\section{The Regional or National Technological Progress Index $(\mathcal{T} \mathcal{P}$-index)}

Table 8.1: $\mathcal{T} \mathcal{P}$-index - Country ranks by technological progress

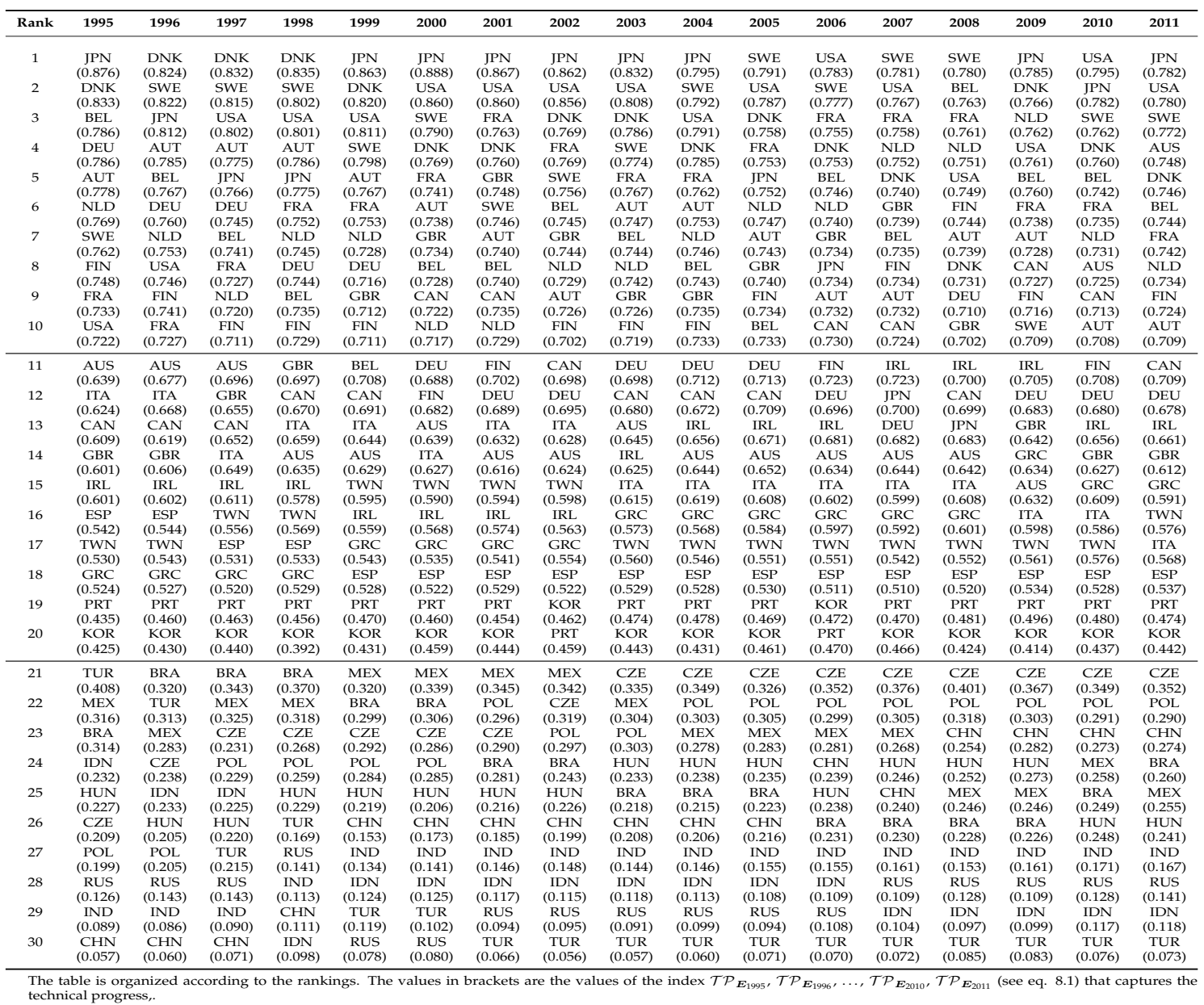

In our view this is the most synthetic measure of national technological progress. Given the framework that we have adopted in this paper, we consider an economic system to be advanced when its methods of production - i.e. the methods actually realized and observed in the real economies - contribute to the formation of the wage-profit frontier. We aggregate the sectoral performance values computed in the previous section, the values $\mathcal{T} \mathcal{P}_{\boldsymbol{E}_{t}}$ for country $j$, to generate a comprehensive measure of national performance.

$$
\mathcal{T P}_{\boldsymbol{E}_{t}}^{j}=\frac{1}{n} \sum_{i=1}^{n} t p_{i}^{j}=\frac{\boldsymbol{e}^{\prime} \mathcal{S} \mathcal{T} \mathcal{P}_{\boldsymbol{E}_{t}}^{j}}{n}
$$

It is easy to see that if all the methods employed in a region or country are superior with respect to alternative methods, the highest attainable value would be equal to the number of commodities, i.e. $n$. But this would a rare case in reality. It is most likely 
that a country is superior or a leader in some sectors and not in others. The $\mathcal{T} \mathcal{P}_{\boldsymbol{E}_{t}}^{j}$ is a measure the technological progress of a system considered as a whole. Table 8.1 reports $\mathcal{T} \mathcal{P}_{\boldsymbol{E}_{t}}^{j}$ values organized by rankings (i.e. from highest values to lowest values).

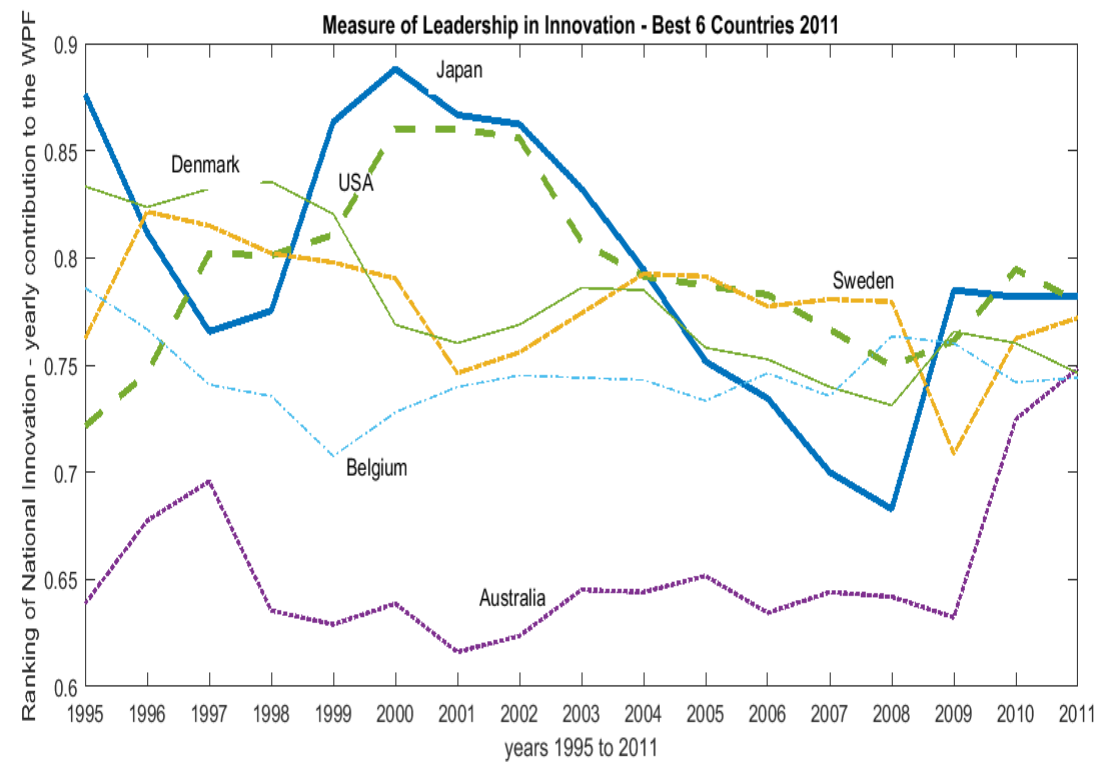

Figure 8.1: The curves report the 6 countries leaders in 2011, with respect to the technological progress, $\mathcal{T} \mathcal{P}_{\boldsymbol{E}_{2009}}$ (see Table 8.1). The highest level is 1, which is relative to the case in which one country would the highest technological progress for all the sectors

\section{Interpreting the results}

We have a vast amount of information that was generated due to availability of the FVZ-algorithm. Given the limited space and scope of this article, we will focus only on a few important results. An observation that readily noticeable is the distance between the individual countries wage-profit curves and the wage-profit frontiers. The values of the $\mathcal{W} \mathcal{P C} \mathcal{C}^{\text {ratio }}$ reported in Table 6.1 are all very far from 1, i.e. values which indicates high distance to the wage-profit frontier. This is interesting because it may indicates that there is an ample room for improving production either thorough specialization or by adopting different production methods. The gap between individual country wage-profit curves and the wage-profit frontier is also evident from Figure 5.2. This indicates the potential that is available for growth. From figures 5.3 and 6.1 we can see that during the period 1995-2002, our indexes indicate that there has been no significant technological progress: the yearly wage-profit frontiers overlap. During the period going from 2003 to 2008 we have had a substantial increase in technological progress: the wage-profit frontiers have moved upwards. There has been a drop since then.

Labour productivity growth reported in Figure 6.2 confirms the pattern of evolution captured by the movement of the wage-profit frontiers. The overall development 
is highly correlated, but the contribution of the different countries vary. For example, the countries with the highest labour productivities in 2011 are somewhat different form those which are ranked first in technological progress, or those with the highest wage-profit curves. From the above observations we can infer that during 2002-2008 there has been an increase in productivity and in technological innovation on the average. During this period, we also observe a convergence in the values determining the relative degrees of innovation. From Figure 8.1, we see that the leadership values converge over time, which indicates that as of 2011, several countries play important roles in determining technological progress. The situation seems to remarkably different compared to the turn of the century, around 2000, where Japan and USA exhibited a high and practically undisputed level of technological progress. This unilateral tendency seems to have decreased over time.

When comparing the rankings given by the two major indexes $\left(\mathcal{W P C}^{\text {ratio }}\right.$-index, and the $\mathcal{T P}$ - index), we observe some interesting differences. At first glance, this diversity in performance may be surprising because a country which is considered to be technologically advanced according to one indicator should also turn out to be advanced when other indicators are considered. This is roughly true for most countries, though not for all. Each index captures different features of the national technological progress and hence it is to be expected that rankings and positions will vary. There are five countries (Denmark, France and Sweden, Netherlands and United States of America) that are always among the top 10 performers across both indexes for the entire time period. The noticeable exclusion from this group are Germany and Japan. in particular Japan has very low values of the wage-profit curve ratio index. It is important to stress that values are all in terms of the purchasing power of a common numéraire, $\eta$. Therefore, a higher wage-profit curve means a higher possible remuneration for the workers of that country. The wage-profit curve associated to a country does assess the "autarkic" capacity of that specific country in production and generating surplus i.e. the potential capacity of being self-sustained.

Our indexes indicate (see Table 6.1 on $\mathcal{W P C}^{\text {ratio }}$ ) that Japan has very low scores, going from being around position 16 (1995 to 2005) to be last, position 30, from 2005 to 2011 and with value zero ${ }^{21}$. When we look at the technological progress index $(\mathcal{T P}$ - index), see Table 8.1, we observe that Japan emerges as a leading performer. This is due to the fact that some sectors are very advanced and more than compensate the relative backwardness of other sectors.

\footnotetext{
${ }^{21}$ This means that Japan from 2005-2011 could not considered as being viable (Chiodi, 1998) for the set of methods that are actually in use. This indicate the fact that the set of methods of production used by Japan dependence to foreign markets for the means of production. This means that relevant production prices that would allow formation of positive profits for all the sectors do not exist. And this explain the values 0 s of the wage-profit frontier ratio
} 


\section{Concluding Remarks}

The main contribution of this paper to the literature on technological progress is the discovery and construction of the FVZ-algorithm, see Section A. This computationally efficient algorithm allows us to construct the efficient wage-profit frontier $w_{E}^{\mathrm{WPF}}(r, \eta)$ (eq. 3.1) and to determine the production possibility frontier, $\Omega^{\mathbf{z}}$ (eq. 2.6) ${ }^{22}$. We argue that the global wage-profit frontier is the robust benchmark against which we can measure the performance of the individual countries.

Identifying the set of methods associated with the frontier, $\mathbf{Z}_{E}^{\mathrm{WPF}},(3.3)$, is important because it allows for an empirical assessment of the actual historical performances of the different countries. Further, we have been able to measure the technological progress at the sectoral level, $\mathcal{S T} \mathcal{P}$ - index (Table 7.1), and subsequently, based on this information, we measure technological progress at the country level, $\mathcal{T} \mathcal{P}-$ index (Table 8.1). We provide a measurement of the historical state of a country through an index that captures the distance between the country wage-profit curve and the global wage-profit frontier, $\mathcal{W} \mathcal{P} \mathcal{C}^{\text {ratio }}$, (Table 6.1).

This study can be extended in various directions. It is worth comparing these results to the more conventional, alternative measures of technical efficiency across countries using Data Envelopment Method or other parametric methods. Another important direction would be to compare the productivities of different sectors by extracting information about the auxiliary prices associated with it. An important feature of our method is that the prices are all measured in terms of a common numéraire, viz., agricultural sector. This means that it is possible to compare the production prices of one local system with another. This information could provide a solid foundation for international comparison of values and for the determination of real exchange rates. Research along this direction may shed a new light on productivities and efficiency comparisons ${ }^{23}$.

A related issue that deserves more attention concerns the differences that exist between actual market prices and the virtual or auxiliary prices. As we have pointed out in Section 2, the assumption of a uniform rate of profit, although very standard, is only a convenient assumption that allows us to work with a simple two dimensional space - instead of a $n$-dimensional space. This could be generalized to include a cloud of profit rates. Furthermore, the knowledge of the set of methods, the matrix, $\mathbf{Z}_{E}^{\mathrm{WPF}}$ (coloreq.3.3), simplifies the task of computing the world Production Possibility Frontier, $\Omega^{\mathrm{z}}$ (eq. 2.6). An interesting further line of research would be to compute the potential gains from trade as outlined by Samuelson $(2001,2004)$ using the results of this paper.

\footnotetext{
${ }^{22}$ To the best of our knowledge, this is the first time the world wage-profit frontier is precisely computed in this framework.

${ }^{23} \mathrm{~A}$ similar attempt has been made, almost 40 years ago, by Wassily Leontief (1985).
} 


\section{A. Computing the wage-profit frontier}

The computation of the wage-profit frontier is a non-trivial exercise ${ }^{24}$. There is a brute force algorithm which allows us to precisely compute the $w_{E}^{\mathrm{WPF}}(r, \eta)$. But the implementation of this algorithm (see below) becomes computationally intractable as the cardinality of the set of methods increases. However, we have been able to devise a tractable algorithm that allows for a drastic reduction in the computational effort. For instance, given the cardinality of the data set that we use in this paper, the computation of $w_{\Phi}^{\text {WPF }}$ using a desktop computer that employs the brute force algorithm would take several decades. In comparison, our algorithm enables us to perform the computation in a few hours.

Precisely identifying the collection of methods contributing to the frontier is the crucial aspect that differentiates our approach in determining the benchmark commodity or the reference technology. The new algorithm allows us to provide a robust measure of productivity and it enables us to develop three new indexes of performance, which will be described in the subsequent sections.

\section{A.1. The brute-force algorithm}

The wage-profit frontier for a given set of methods can be derived by computing the wage-profit curves relative to each combinations of methods.

1. input data, i.e. individual input-output tables and organize them into a multiple dimension array, $\boldsymbol{\Phi}$ (see equation 2.2)

2. enumerate all possible combinations of methods $\boldsymbol{E}_{\boldsymbol{\Phi}}=\left\{\mathbf{z}_{\mathrm{j}}\right\}$ with $j=1, \ldots, s$ with $\boldsymbol{s}=\prod_{i=1}^{n} s_{i}$.

3. compute the wage-profit curve, $w^{\mathbf{z}_{j}}$, eq. 2.11 sequentially for $j=1$ to $s$ and retain the value for wages $w$ that dominate the previously computed wage-profit curves. If $\boldsymbol{E}_{\{j\}}$ is the set of combinations $\mathbf{z}$ enumerated from 1 to $j$, the following recursive computation is made until $j=s$.

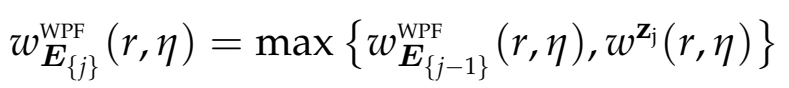

However, we can observe that the combinatorial and computational complexity associated with the implementation of this algorithm is very high. In the database that we use, there are 31 sectors and 30 countries. This means that in order to determine the yearly wage-profit frontier we need to compute $31^{30} \approx 5.5 * 10^{44}$ wage-profit curves. There are 15 years of observations, hence the computation of the intertemporal wageprofit frontier would be in the order of $\left(31^{30}\right)^{15} \approx\left(1.29 * 10^{41}\right)^{15} \geq 10^{671}$.

\footnotetext{
${ }^{24}$ Properties of the wage-profit frontier are listed above in Section 3.
} 
This shows that such computation is practically impossible in the sense that a brute-forced algorithm would not compute the wage-profit frontier and won't halt within any reasonable time frame.

\section{A.2. The FVZ-algorithm}

The computational complexity, however, can be drastically reduced if we employ the new algorithm that we have constructed. We call this algorithm the FVZ-algorithm ${ }^{25}$.

Bharadwaj (1970) has shown that:

i) "At a switch point the adjacent production system differs in the method of production for only one of the commodities common to them (Bharadwaj (1970) (p.423), emphasis added)";

ii) "The choice of the value unit [the numéraire] does not affect the maximum number of switching possibilities [and their correspondence to the profit rate](Bharadwaj (1970) (p.424))"

Using any point on any frontier, the following procedure climbs the individual wage-profit frontiers using the switch points as if they were steps on a ladder. This is what facilitates the drastic reduction in the computational time.

The brute-force algorithm requires the computation of an astronomical number of wage-profit curves. In contrast, the computation using the FVZ-algorithm would require a computation which is a multiple of the cardinality of the set of methods. Let us take the case in which all the methods are considered, i.e., the methods relative to 17 years for 30 countries and 31 industries. In this case, the worst case computation associated with our new algorithm would only require computing a small multiple of $15810(=17 \times 30 \times 31)$ wage-profit curves. This is the total number of rows in the set of available methods $\Phi$.

As we will see below, for each profit rate, the algorithm requires at most 15810 (minus 31) alternative set of methods $\mathbf{z}$ to be tried out before moving on to the values associated with the profit rates to the left or to the right. This algorithm requires spanning the domain from left to right and from right to left until no new dominating combinations are found. In the worst case scenario, the domain has to be spanned 15810 times. This is an upper bound requiring circa $2.5 \times 10^{8}\left(\approx(17 \times 30 \times 31)^{2}=\right.$ $15810^{2}$ ) computations of wage-profit curves before the wage-profit frontier is computed with absolute precision. In our experience, wage-profit frontier is found by spanning of the domain a maximum of 5 times. In this case, the number of wage-profit curves to be computed is (still for the worst case scenario) $5 \times 15810\left(\approx 7.9 \times 10^{4}\right)$. This is a relatively very small (and computationally manageable) number of wage-profit curves that we have to compute.

\footnotetext{
${ }^{25}$ Velupillai and Zambelli (1993) took the first step in this direction. Zambelli and Fredholm (2010) first saw the opportunity to exploit the theoretical properties of the wage-profit frontier presented in Bharadwaj (1970). We take the liberty to call the algorithm - FVZ-algorithm (Fredholm-VelupillaiZambelli).
} 
Algorithm 1 VFZ Algorithm

\section{Inputs}

1: individual input-output tables organized into a multi-dimensional array having the structure $\boldsymbol{\Phi}$ (see equation 2.2) or of a subset of it, $\mathbf{E}_{\boldsymbol{\Phi}}$.

\section{Initialization}

2: $n \leftarrow\{$ no. of industries or commodities $\}$

3: $\mathbf{s} \leftarrow$ \{no. of alternative methods per commodity

$\triangleright \mathbf{s}_{n \times 1}=\left[s_{1}, s_{2}, \ldots, s_{i}, \ldots, s_{n}\right]^{\prime}$, where $s_{i}$ is the maximum number of alternative methods observed for the production of commodity $i=1, \ldots, n$.

4: $\mathbf{z} \leftarrow$ \{ initial combination of methods\}

$\triangleright \mathbf{z}_{n \times 1}=\left[z_{1}, z_{2}, \ldots, z_{i} \ldots, z_{n}\right]^{\prime}$, where each $z_{i}$ indicates the method chosen for the production of commodity $i, z_{i} \in\left[1, s_{i}\right]$. Pick any one $z_{i}$ among the possible combinations of methods

5: $\mathbf{A}^{\mathbf{z}}, \mathbf{L}^{\mathbf{Z}}$ and $\mathbf{B}^{\mathbf{z}}$ respectively.

6: $\eta_{n \times 1} \leftarrow$ Choice of a numeraire $\}$

$\triangleright$ The specific choice of the numéraire here is unimportant. The numéraire is useful for computing the wage-profit curves and prices, but not for determining the methods at the frontier.

7: $h \leftarrow$ Step-Size of the domain of the wage-profit-frontier $\}$

8: $w^{\mathbf{z}}(r, \eta) \leftarrow$ Computed as in equation 2.11\} where $r=\left[0, h, 2 h, 3 h, \ldots, \mathcal{R}^{\mathbf{z}}\right]$.

$\triangleright$ It is likely that $\mathcal{R}^{\mathbf{z}}$ may not be a multiple of $h$. For the simplicity of the exposition, we assume that it is.

9: $\mathcal{R}^{\max } \leftarrow \mathcal{R}^{\mathbf{z}}$

10: $\mathbf{F} \leftarrow\left\{\right.$ Matrix with $n$ rows and $\left(\frac{\mathcal{R}^{\max }}{h}+1\right)$ columns, where each column is the vector $\left.\mathbf{z}\right\}$

$\triangleright$ Matrix $\mathbf{F}$ would have as many columns as the number of points in the domain of the wage-profit frontier (i.e. $r=\left[0, h, 2 h, 3 h, \ldots, \mathcal{R}^{\mathbf{z}}\right]$ ). The columns of $\mathbf{F}$ change one by one as candidate methods for the frontier, i.e. new $\mathbf{z}$, are found.

11: $r^{*} \leftarrow \mathcal{R}^{\mathbf{z}}$.

12: Replacement $\leftarrow 1$

$\triangleright$ Control variable

\section{Computing WPF}

13: procedure COMPUTATION OF WPF

14: [Start Spanning]

15: $\quad$ if Replacement $=0$ then

16: $\quad$ GO TO 86 (Routine 3)

17: $\quad$ else if Replacement $=1$ then

18: $\quad$ Replacement $\leftarrow 0$

19: end if

Routine 1: Span Right-to-Left 


\section{Subroutine 1A: New Profit Rate}

20: $\quad r_{-}^{*} \leftarrow r^{*}-h$

21: $\quad$ if $r_{-}^{*}<0$ then

22: $\quad r^{*} \leftarrow r_{-}^{*}$ and GO TO 52 [Subroutine 2A: New Profit Rate]

23: $\quad$ end if

24: $\quad \mathbf{z}^{\text {old }} \leftarrow$ Column of $\mathbf{F}$ associated with $\left.r_{-}^{*}\right\}$

$\triangleright$ The methods associated with $r^{*}$

25: Compute and organize $\mathbf{A}^{\mathbf{z}^{\text {old }}}, \mathbf{L}^{\mathbf{z}^{\text {old }}}$ and $\mathbf{B}^{\mathbf{z}^{\text {old }}}$ as in equations 2.3, 2.4 and 2.5, respectively

26: $\quad \bar{w}^{\mathbf{z}^{\text {old }}}\left(r_{-}^{*}, \eta\right) \leftarrow$ Computed as in equation 2.11$\}$

$\triangleright$ Wage value associated with profit rate $r_{-}^{*}$

27: $\quad \mathbf{z}^{\text {new }} \leftarrow \mathbf{z}^{\text {old }} ; \mathbf{A}^{\text {new }} \leftarrow \mathbf{A}^{\text {old }} ; \mathbf{L}^{\text {new }} \leftarrow \mathbf{L}^{\text {old }} ; \mathbf{B}^{\text {new }} \leftarrow \mathbf{B}^{\text {old }}$

\section{Subroutine 1B: Repeat}

28: $\quad i \leftarrow 0$

29: $\quad \bar{w}^{\mathbf{z}^{\text {new }}}\left(r_{-}^{*}, \eta\right) \leftarrow \bar{w}^{\mathbf{z}^{\text {old }}}\left(r_{-}^{*}, \eta\right)$

30: $\quad$ while $\bar{w}^{\text {zew }}\left(r_{-}^{*}, \eta\right) \leq \bar{w}^{\mathbf{z}^{\text {old }}}\left(r_{-}^{*}, \eta\right)$ and $i \leq n$ do

31: $\quad i \leftarrow i+1$

32: $\quad j \leftarrow 0$

$\triangleright$ Identifies the industry producing commodity $i$

33: $\quad$ while $j \leq s_{i}$ do

34: $\quad j \leftarrow j+1$

35: $\quad z_{i}^{\text {new }} \leftarrow j$

36: $\quad \mathbf{A}^{\text {new }}(i,:) \leftarrow \mathbf{E}_{\boldsymbol{\Phi}}(j, 1: n, i)$

$\triangleright$ Replaces row $i$, with method $j$ for the production of commodity $i$

37: $\quad \mathbf{L}^{\text {new }}(i, 1) \leftarrow \mathbf{E}_{\boldsymbol{\Phi}}(j, n+1, i)$

38: $\quad \mathbf{B}^{\text {new }}(i, 1) \leftarrow \mathbf{E}_{\boldsymbol{\Phi}}(j, n+2, i)$

39: $\quad \bar{w}^{\mathbf{z}^{\text {new }}}\left(r_{-}^{*}, \eta\right) \leftarrow$ Computed as in equation 2.11$\}$

40: $\quad \mathbf{A}^{\text {new }} \leftarrow \mathbf{A}^{\text {old }} ; \mathbf{L}^{\text {new }} \leftarrow \mathbf{L}^{\text {old }} ; \mathbf{B}^{\text {new }} \leftarrow \mathbf{B}^{\text {old }}$

41: $\quad$ end while

42: $\quad$ end while

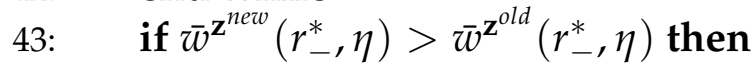

44: $\quad \mathbf{z}^{\text {old }} \leftarrow \mathbf{z}^{\text {new }} ; \mathbf{A}^{\text {old }} \leftarrow \mathbf{A}^{\text {new }} ; \mathbf{L}^{\text {old }} \leftarrow \mathbf{L}^{\text {new }} ; \mathbf{B}^{\text {old }} \leftarrow \mathbf{B}^{\text {new }} ; \bar{w}^{\mathbf{z}^{\text {old }}}\left(r_{-}^{*}, \eta\right) \leftarrow$ $\bar{w}^{\mathbf{z}^{\text {new }}}\left(r_{-}^{*}, \eta\right)$

45: $\quad$ Replacement $\leftarrow 1$;

46: $\quad \mathbf{F}$ (column associated with $\left.r_{-}^{*}\right) \leftarrow \mathbf{z}^{\text {new }}$

47: $\quad \mathcal{R}^{\max } \leftarrow \max \left(\mathcal{R}^{\max }, \mathcal{R}^{\mathbf{z}^{\text {new }}}\right)$ and change the domain of $r$ and the number of columns of $\mathbf{F}$ accordingly.

48: $\quad$ GO TO 28 [Subroutine 1B: Repeat]

49: $\quad$ else

50: $\quad$ GO TO 20 [Subroutine 1A: New Profit Rate]

51: $\quad$ end if 


\section{Routine 2: Span Left-to-Right}

\section{Subroutine 2A: New Profit Rate}

52: $\quad r_{+}^{*} \leftarrow r^{*}+h$

53: $\quad$ if $r_{-}^{*}>\mathcal{R}^{\text {max }}$ and Replacement $=1$ then

54: $\quad r^{*} \leftarrow r_{+}^{*}$ and GO TO 20 [Subroutine 1. New Profit Rate]

55: else GO TO 86 [Subroutine 3]

56: $\quad$ end if

57: $\quad \mathbf{z}^{\text {old }} \leftarrow$ Column of $\mathbf{F}$ associated with $\left.r_{+}^{*}\right\}$

$\triangleright$ Methods associated with $r_{+}^{*}$

58: Compute and organize $\mathbf{A}^{\mathbf{z}^{\text {old }}}, \mathbf{L}^{\mathbf{z}^{\text {old }}}$ and $\mathbf{B}^{\mathbf{z}^{\text {old }}}$ as in equations 2.3, 2.4 and 2.5, respectively.

59: $\quad \bar{w}^{\mathbf{z}^{\text {old }}}\left(r_{+}^{*}, \eta\right) \leftarrow$ Computed as in equation 2.11$\}$

$\triangleright$ Wage value associated with profit rate $r_{+}^{*}$.

60: $\quad \mathbf{z}^{\text {new }} \leftarrow \mathbf{z}^{\text {old }} ; \mathbf{A}^{\text {new }} \leftarrow \mathbf{A}^{\text {old }} ; \mathbf{L}^{\text {new }} \leftarrow \mathbf{L}^{\text {old }} ; \mathbf{B}^{\text {new }} \leftarrow \mathbf{B}^{\text {old }}$

\section{Subroutine 2B: Repeat}

61: $\quad i \leftarrow 0$

62: $\quad \bar{w} \bar{w}^{\text {zew }}\left(r_{+}^{*}, \eta\right) \leftarrow \bar{w}^{\mathbf{z}^{\text {old }}}\left(r_{+}^{*}, \eta\right)$

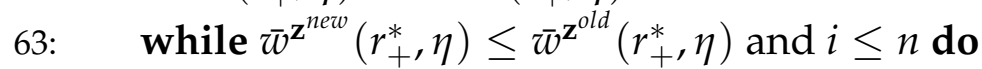

64: $\quad i \leftarrow i+1$

65: $\quad j \leftarrow 0$

$\triangleright$ Identifies the industry producing commodity $i$

66: $\quad$ while $j \leq s_{i}$ do

67: $\quad j \leftarrow j+1$

68: $\quad z_{i}^{\text {new }} \leftarrow j$;

69: $\quad \mathbf{A}^{n e w}(i,:) \leftarrow \mathbf{E}_{\boldsymbol{\Phi}}(j, 1: n, i)$

$\triangleright$ Replaces row $i$, with method $j$ for the production of commodity $i$.

70: $\quad \mathbf{L}^{\text {new }}(i, 1) \leftarrow \mathbf{E}_{\boldsymbol{\Phi}}(j, n+1, i)$

71: $\quad \mathbf{B}^{\text {new }}(i, 1) \leftarrow \mathbf{E}_{\boldsymbol{\Phi}}(j, n+2, i)$

72: $\quad \bar{w}^{\mathbf{z}^{\text {new }}}\left(r_{-}^{*}, \eta\right) \leftarrow$ Computed as in equation 2.11$\}$

73: $\quad \mathbf{A}^{\text {new }} \leftarrow \mathbf{A}^{\text {old }} ; \mathbf{L}^{\text {new }} \leftarrow \mathbf{L}^{\text {old }} ; \mathbf{B}^{\text {new }} \leftarrow \mathbf{B}^{\text {old }}$

74: $\quad$ end while

75: $\quad$ end while

76: $\quad$ if $\bar{w}^{\mathbf{z}^{\text {new }}}\left(r_{+}^{*}, \eta\right)>\overline{w^{\mathbf{z}^{o l d}}}\left(r_{+}^{*}, \eta\right)$ then

77: $\quad \mathbf{z}^{\text {old }} \leftarrow \mathbf{z}^{\text {new }} ; \mathbf{A}^{\text {old }} \leftarrow \mathbf{A}^{\text {new }} ; \mathbf{L}^{\text {old }} \leftarrow \mathbf{L}^{\text {new }} ; \mathbf{B}^{\text {old }} \leftarrow \mathbf{B}^{\text {new }} ; \bar{w}^{\mathbf{z}^{\text {old }}}\left(r_{+}^{*}, \eta\right) \leftarrow$ $\bar{w}^{\mathbf{z}^{\text {new }}}\left(r_{+}^{*}, \eta\right)$

78: $\quad$ Replacement $\leftarrow 1$;

79: $\quad \mathbf{F}\left(\right.$ column associated with $\left.r_{+}^{*}\right) \leftarrow \mathbf{z}^{\text {new }}$

80: $\quad \mathcal{R}^{\max } \leftarrow \max \left(\mathcal{R}^{\max }, \mathcal{R}^{\mathbf{z}^{\text {new }}}\right)$ and change the domain of $r$ and the number of columns of $\mathbf{F}$ accordingly. 
81: $\quad$ GO TO 61 [Subroutine 2B. Repeat]

82: $\quad$ else

83: $\quad$ GO TO 52 [Subroutine 2A. New Profit Rate]

84: $\quad$ end if

85: $\quad$ GO TO 14 [Start Spanning]

Routine 3: Extracting Frontier Methods

86: Indices of the set of frontier methods are found in the matrix $\mathbf{F}$. Each column of $\mathbf{F}$ is associated, one to one, with the elements of the profit rates $r \in$ $\left[0, h, 2 h, 3 h, \ldots, \mathcal{R}^{\max }\right]$. Compute the switch points and the intervals composing the wage-profit frontier, $w_{\boldsymbol{E}_{\boldsymbol{\Phi}}}^{\mathrm{WPF}}(r, \eta)$ (eq. 3.1), directly from the information embedded in $\mathbf{F}$ and $r \in\left[0, h, 2 h, 3 h, \ldots, \mathcal{R}^{\max }\right]$, simply by eliminating adjacent columns which are equal in $\mathbf{F}$. The resulting matrix is $\mathbf{Z}_{\boldsymbol{E}_{\boldsymbol{\Phi}}^{\mathrm{WP}}}^{\mathrm{WP}}$ (eq. 3.3). Two adjacent columns, say $\mathbf{j}$ and $j+1$ of $\mathbf{Z}_{\boldsymbol{E}_{\boldsymbol{\Phi}}}^{\mathrm{WPF}}$ identify the methods coexisting at the switch point $j$. The $j^{\text {th }}$ column of $\mathbf{Z}_{\boldsymbol{E}_{\boldsymbol{\Phi}}}^{\mathrm{WPF}}$ identifies the combination of methods defining the wage-profit curve to the left of the switch point and $(j+1)^{\text {th }}$ identifies those combination of methods to the right of the switch point.

87: end procedure 
Afriat, S. N., 2003. The Market: equilibrium, stability, mythology. Routledge, London and New York.

Arrow, K., 1951. Alternative proof of the substitution theorem for Leontief models in the general case. In: Koopmans, T. (Ed.), Activity Analysis of Production and Allocation. John Wiley, New York, pp. 155-164.

Bharadwaj, K., 1970. On the Maximum Number of Switches Between Two Production Systems. Schweizerische Zeitschrift für Volkswirtschaft und Statistik 106 (4), 409429.

Bogetoft, P., 1996. DEA on Relaxed Convexity Assumptions. Management Science $42(3), 457-465$.

Bogetoft, P., Tama, J., Tind, J., 2000. Convex Input and Output Projections of Nonconvex Production Possibility Sets. Management Science 46 (6), 858-869.

Bruno, M., 1969. Fundamental duality relations in the pure theory of capital and growth. Review of Economic Studies 36 (1), 39-53.

Bruno, M., Burmeister, E., Sheshinski, E., 1966. The nature and implications of the reswitching of techniques. Quarterly Journal of Economics 80 (4), 526-553.

Cekota, J., 1988. Technological change in canada (1961-80): An application of the surrogate wage function. The Canadian Journal of Economics / Revue canadienne d'Economique 21 (2), pp. 348-358.

Charnes, A., Cooper, W. W., Rhodes, E., 1978. Measuring the efficiency of decision making units. European Journal of Operational Research (6), 429-444.

Chiodi, G., 1998. On non-self-replacing states. Metroeconomica 49 (1), 97-107.

Diamond, P. A., 1965. National debt in a neoclassical growth model. American Economic Review 55 (5), pp.1126-1150.

Farrell, M., 1957. The measurement of productive efficiency. Journal of the Royal Statistical Society. Series A (General). 120 (3), 253-290.

Felipe, J., McCombie, J., 2013. The aggregate production function and the measurement of technical change. "Not Even Wrong". Edward Elgar Publishing.

Fried, H., Lovell, K., Schmidt, S. (Eds.), 2008. The Measurement of Productive Efficiency and Productive Growth. Oxford University Press, New York.

Garegnani, P., 1966. Switching of techniques. Quarterly Journal of Economics 80 (4), 554-567.

Han, Z., Schefold, B., 2006. An empirical investigation of paradoxes: reswitching and reverse capital deepening in capital theory. Cambridge Journal of Economics 30, 737-765. 
Hicks, J. R., 1965. Capital and Growth. Oxford University Press, Oxford.

Koopmans, T., 1951. Alternative proof of the substitution theorem for leontief models in the case of three industries. In: Koopmans, T. (Ed.), Activity Analysis of Production and Allocation. John Wiley \& Sons, New York, pp. 33-97.

Krelle, W., 1977. Basic facts in capital theory. some lessons from the controversy in capital theory. Rvue d'Economie Politique 87, 282-329.

Kumar, S., Russell, R. R., 2002. Technological change, technological catch-up, and capital deepening: Relative contributions to growth and convergence. American Economic Review 92 (3), 527-548.

Kurz, H., Salvadori, N., 1995. Theory of Production. A Long-Period Analysis. Cambridge University Press.

Kurz, H., Salvadori, N., 2006. InputOutput analysis from a wider perspective: a comparison of the early works of Leontief and Sraffa. Economic Systems Research 18 (4), 373-390.

Leontief, W., 1985. Input-Output Economics. Oxford University Press, New York, Ch. Technological Change, Prices, Wages, and Rates of Return on Capital in the U.S. Economy, Chapter 19, pp. 392-417.

Mariolis, T., Tsoulfidis, L., 2011. Eigenvalue distribution and the production priceprofit rate relationship: theory and empirical evidence, evolutionary and institutional. Evolutionary and Institutional Economics Review 8 (1), pp. 87-122.

Mariolis, T., Tsoulfidis, L., 2016. Values, Prices and Income Distribution in Actual Economies. Springer Verlag.

Mas-Colell, A., Whinston, M. D., Green, J., 1995. Microeconomic Theory. Oxford University Press, New York.

Ochoa, E. M., 1989. Values, prices and wage profit curves in the US economy. Cambridge Journal of Economics 13, 413-29.

O'Mahony, M., Timmer, M. P., 2009. Output, input and productivity measures at the industry level: The EU KLEMS database. The Economic Journal 119 (538), F374F403.

Ozol, C., 1984. Parable and realism in production theory: The surrogate wage function. The Canadian Journal of Economics / Revue canadienne d'Economique 17 (2), pp. 353-368.

Pasinetti, L., 1966. Changes in the rate of profits and switches of techniques. Quarterly Journal of Economics 80 (4), pp. 503-517.

Pasinetti, L., 1977. Lectures on the Theory of Production. Columbia University Press, New York. 
Petersen, N., 1990. Data envelopment analysis on a relaxed set of assumptions. Management Science 36 (3), 305-314.

Robinson, J., 1953. The Production Function and the Theory of Capital. Review of Economic Studies 21 (2), pp. 81-106.

Samuelson, P. A., 1951. Abstract of a Theorem Concerning Substitutability in Open Leontief Models. In: Koopmans, T. (Ed.), Activity Analysis of Production and Allocation. John Wiley, New York.

Samuelson, P. A., 1962. Parable and realism in capital theory: the surrogate production function. Review of Economic Studies 29 (3), 193-206.

Samuelson, P. A., 2001. A Ricardo-Sraffa Paradigm Comparing Gains from Trade in Inputs and Finished Goods. Journal of Economic Literature 39 (4), 1204-1214.

Samuelson, P. A., 2004. Where Ricardo and Mill rebut and confirm arguments of mainstream economists supporting globalization. Journal of Economic Perspectives 18 (3), 135-146.

Sato, K., 1974. The neoclassical postulate and the technology frontier in capital theory. Quarterly Journal of Economics 88 (3), 353-384.

Schefold, B., 2013. Approximate production functions. Cambridge Journal of Economics 37, 1161-1184.

Shaikh, A., 1988. The empirical strength of the labor theory of value. In: Bellofiore, R. (Ed.), Conference Proceedings of Marxian Economics: A Centenary Appraisal. Macmillan, London.

Shaikh, A., 2012. The empirical linearity of Sraffa's critical output-capital ratios. In: Gerke, C., Salvadori, N., Steedman, I., Sturn, R. (Eds.), Classical Political Economy and Modern Theory. Essays in Honour of Heinz Kurz. Routledge.

Shaikh, A., 2016. Capitalism: Competition, Conflict, Crises. Oxford University.

Shephard, R., 1970. Theory of Cost and Production Functions. Princeton University Press, New Jersey.

Sraffa, P., 1925. Sulle relazioni tra costo e quantit prodotta. Annali di Economia, 277328.

Sraffa, P., 1926. Law of returns under competitive conditions. Economic Journal, 535550.

Sraffa, P., 1960. Production of Commodities by Means of Commodities. Cambridge University Press, Cambridge. 
Timmer, M. (Ed.), 2012. The World Input-Output Database (WIOD): Contents, Sources and Methods, WIOD Working Paper Number 10, April 2012, downloadable at http:/ / www.wiod.org/publications/papers/wiod10.pdf. EU - 7th Framework Programme.

Velupillai, K., Zambelli, S., 1993. The international comparisons programme and production based indices of economic performances. mimeo, World Bank, Washington.

Zambelli, S., 2004. The $40 \%$ neoclassical aggregate theory of production. Cambridge Journal of Economics 28 (1), 99-120.

Zambelli, S., 2017. The aggregate production function is NOT neoclssical. Cambridge Journal of Economics In Print - Forthcoming - Accepted for publication.

Zambelli, S., Fredholm, T., 2010. An Algorithmic Measurement of Technical Progress. ASSRU Discussion Paper, No. 6-2010, Algorithmic Social Sciences Research Unit, University of Trento. 